بحث رقم 1

المجلد الثالث، العدد الثالث، 154:140

أيلول (2021)

\title{
بَلاغةُ الوصفِ في حَديثِ أمَّ مَعْبَد
}

\author{
وليد محمود أبو ندى \\ أستاذ دكتور في كلية الآداب- قسم اللغة العربية لدوى \\ الجامعة الإسلامية- غزة- فلسطين \\ wnada@iugaza.edu.ps
}


المجلة الدولية للدراسات اللغوية والأدبية العببية

International Journal for Arabic Linguistics and Literature Studies (JALLS)

www.refaad.com

Journal Homepage: https://www.refaad.com/views/JALS/home.aspx ISSN : 2663-5860(Online) 2663-5852(Print)

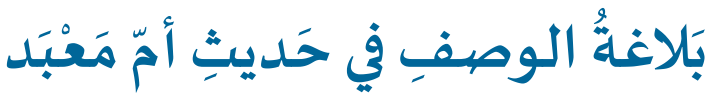 \\ وليد محمود أبو ندى}

أستاذ دكتور في كلية الآداب- قسم اللغة العربية- الجامعة الإسلامية- غزة- فلسطين

wnada@iugaza.edu.ps

DOI: https://doi.org/10.31559/JALLS2021.3.3.1 2021/8/7 2021/5/10 مراجعة البحث: 2021/6/20 قبول البحث البحث: 2010/20

الملتخص:

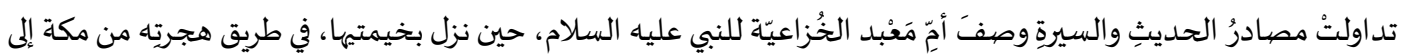

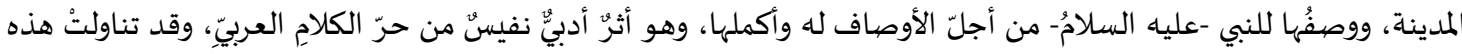

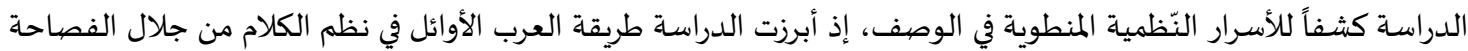
وحلو الألفاظ وبهاء التراكيب وقصد المعنى وجمال الإيقاع وحسن الجَرْس، لا سيما الموصهوف أكمل الخَلْقِ نوراً وبهاءً جمالاً، فاكتملَ الوصفُ بكمالِ موصوفه وبلاغِية واصفهـ. الكلمات المفتاحيّة: بلاغة؛؛ وصف؛ حديث نبوي؛ أمّ معبد.

تداولت مصادر الحديث السيرة النبوية قصةّة أم معبد الخُزاعيّة التي مرَّ الرسولُ -صلى الله عليه وسلمَّ- بخيمتيها؛ مهاجراً من مكة

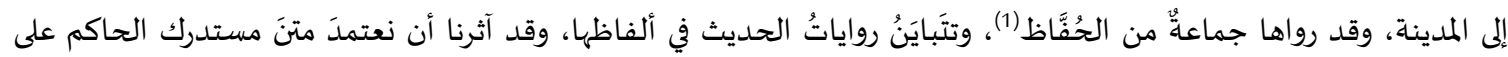

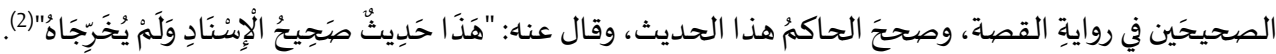

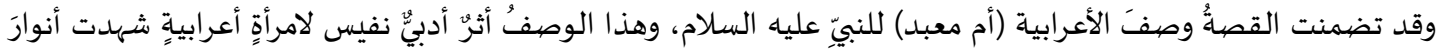

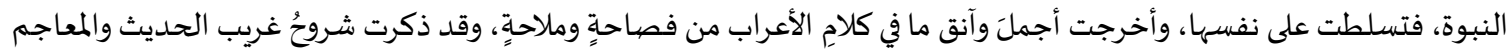

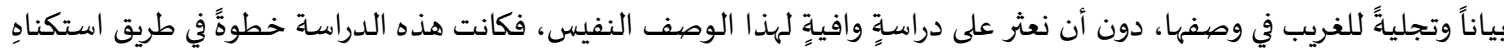

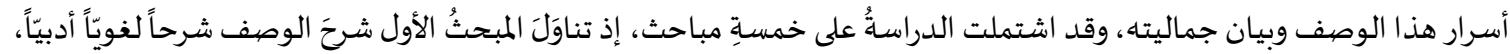

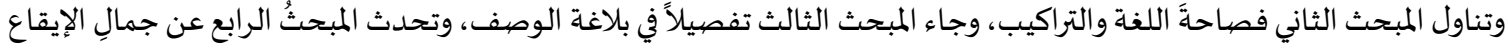

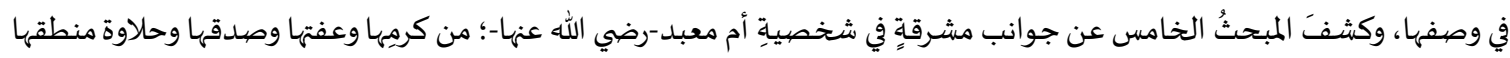

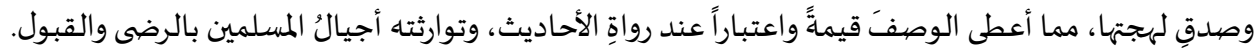

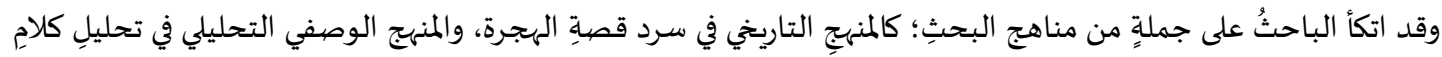

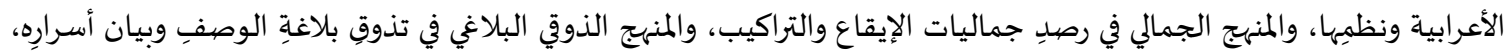
والمنهج النفسي في استِكناه شخصيةٍ أم معبد.

(1) منهم: ابن الأثير في شرح الطوال الغرائب، 172، والسيوطي في الخصائص الكبرى، 466/1، والهيثمي في المجمع 6/55، 8/6 278، 263/9، والزمخشري في الفائق، 94/ 94، وابن كثير في السيرة، 2 / 257.

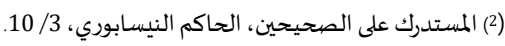




\section{المبحَثُ الأولُ: شرحُ وصِفِ أمّ مَعْبد}

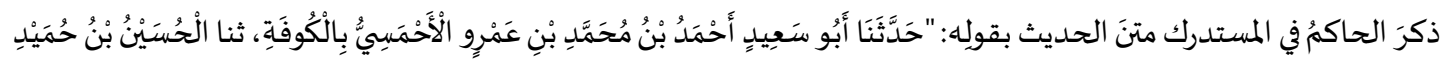

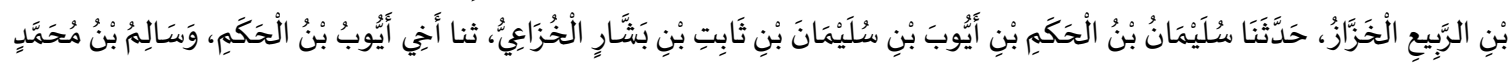

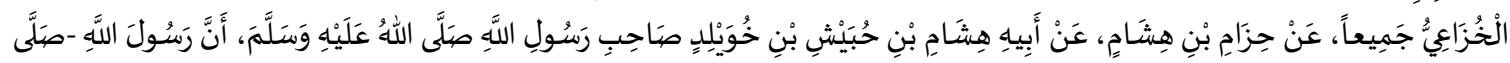

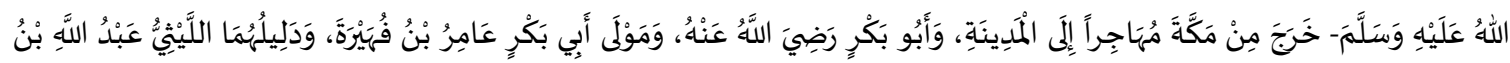

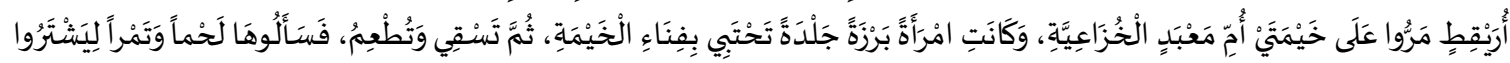

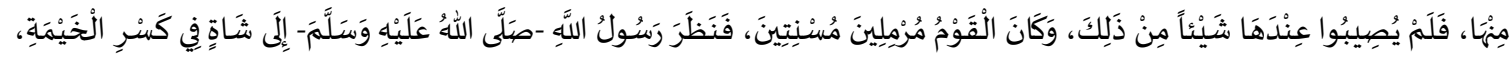

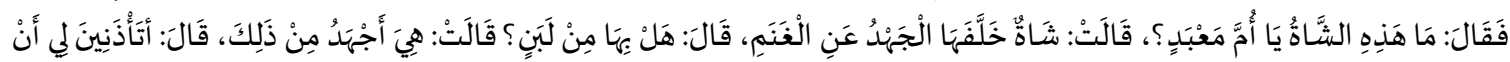

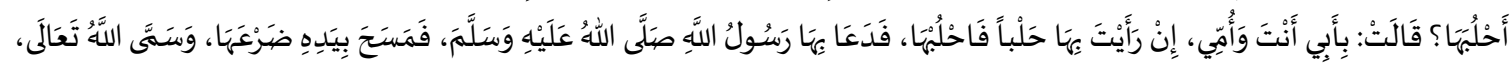

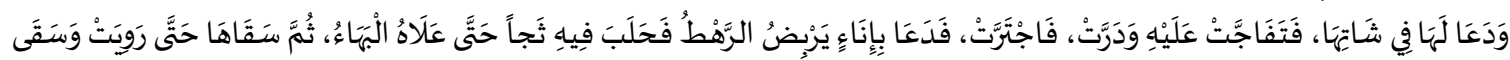

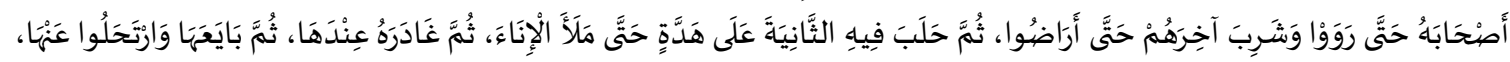

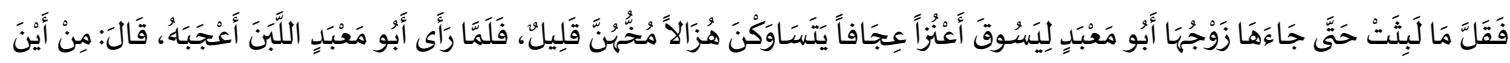

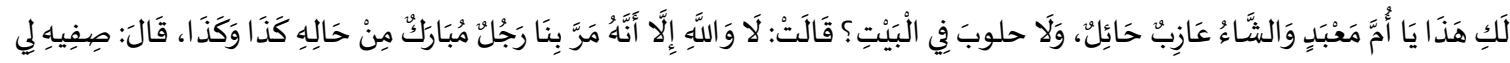

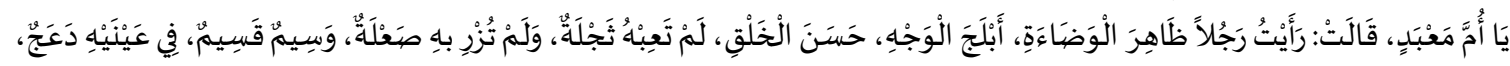

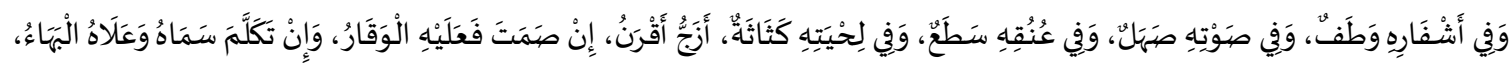

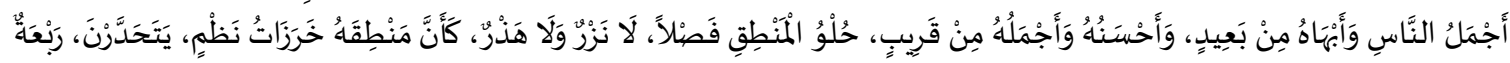

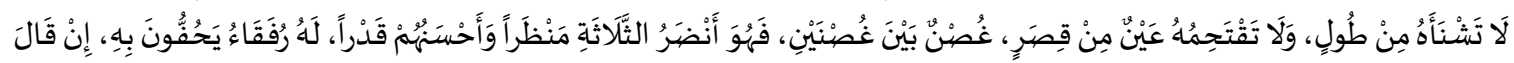

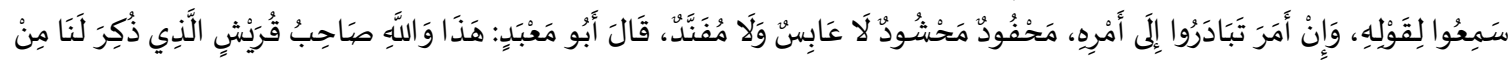

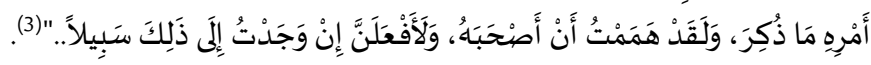

أولاً: شرح الوصف:

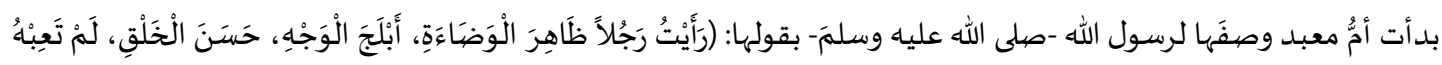

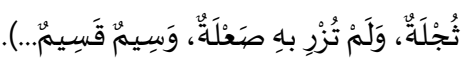

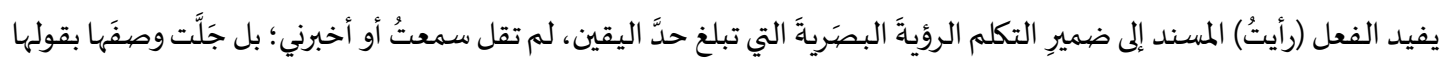

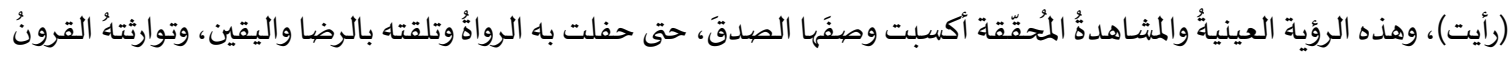

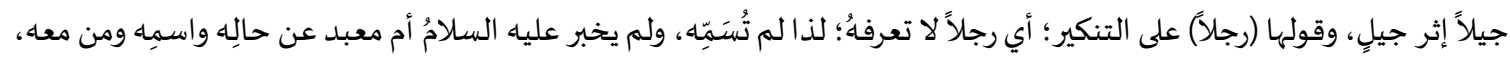

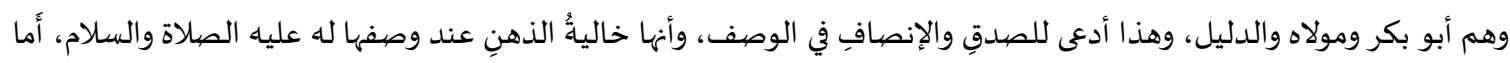

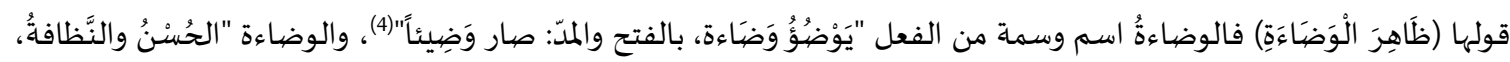

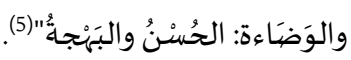

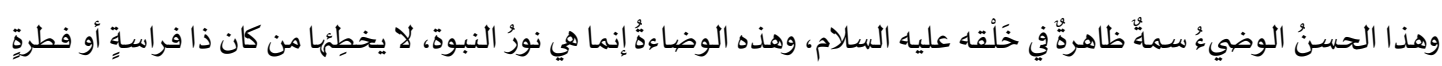

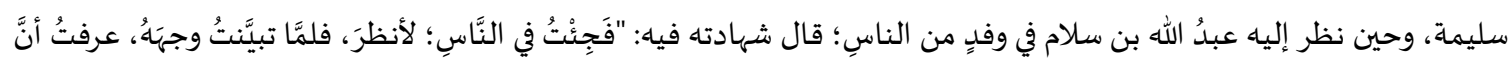

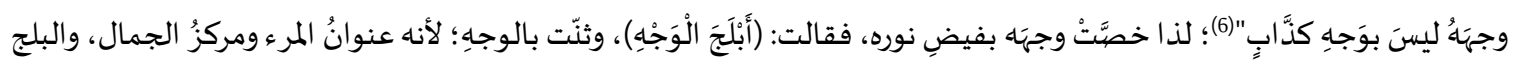

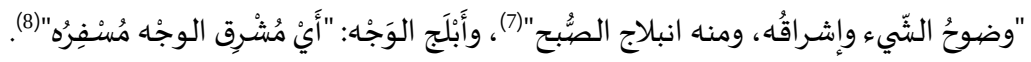

(3) (3) المستدرك على الصحيحين، 10/3.

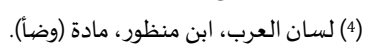

(5) (5) (5) لسان العرب، مادة (وضاً).

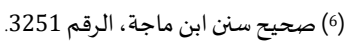

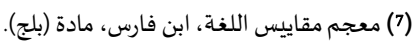

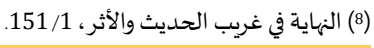




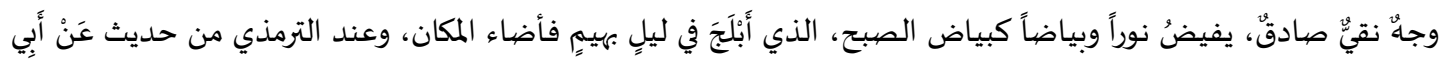

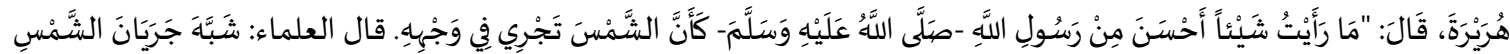

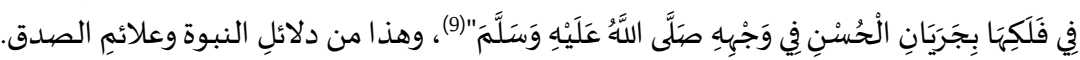

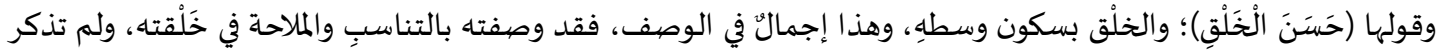

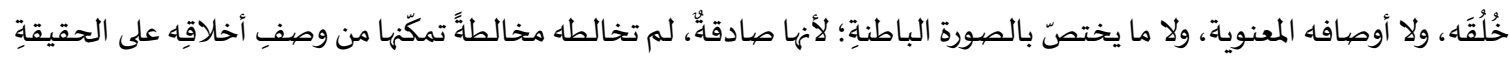

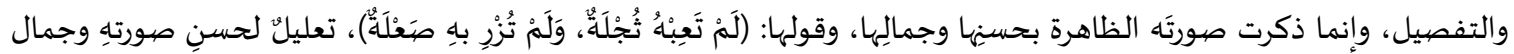

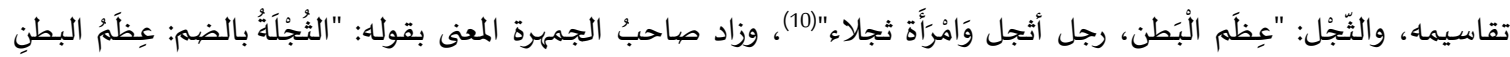

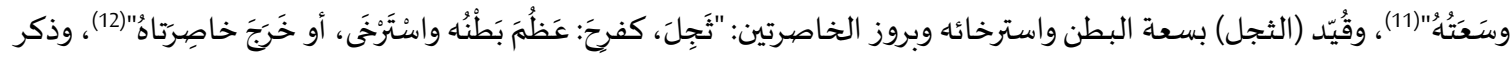

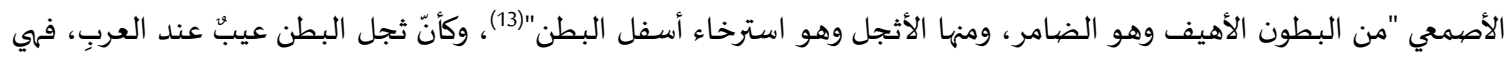

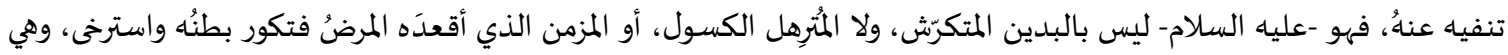

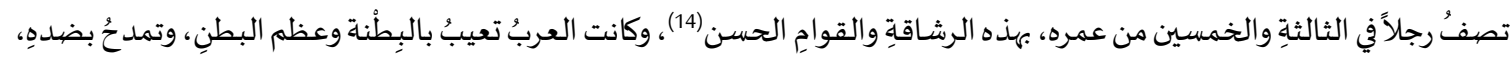
ومنه قول الشاعر:

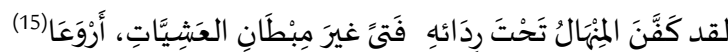

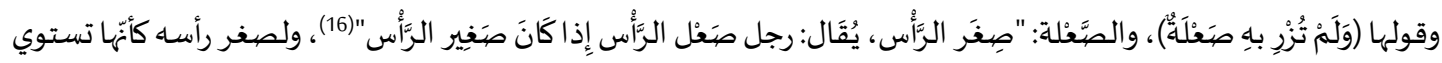

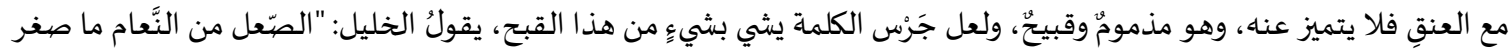

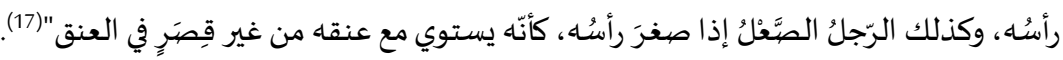

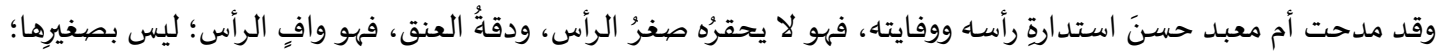

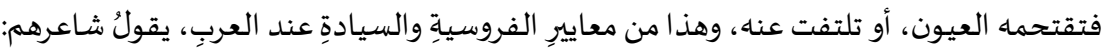

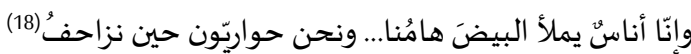

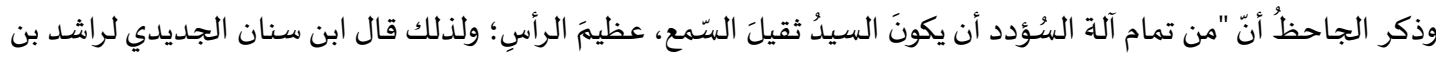

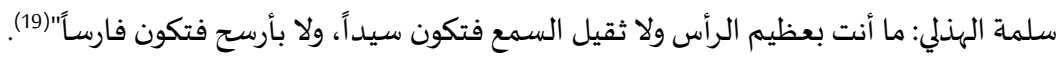

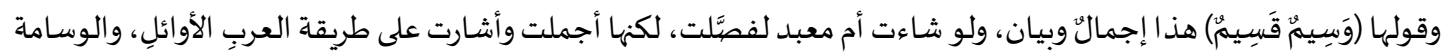

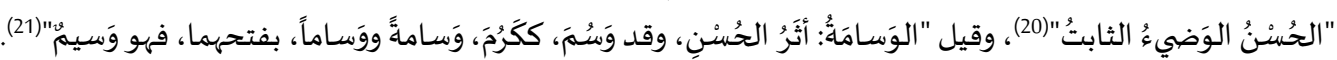

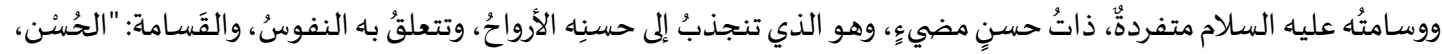

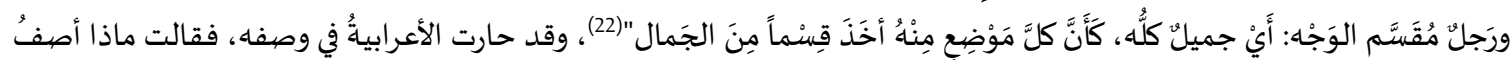

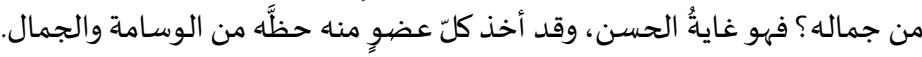

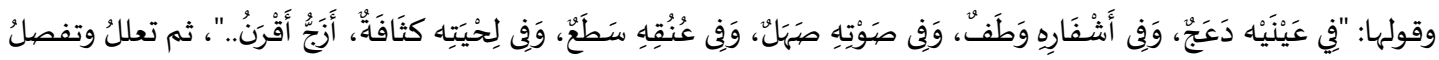

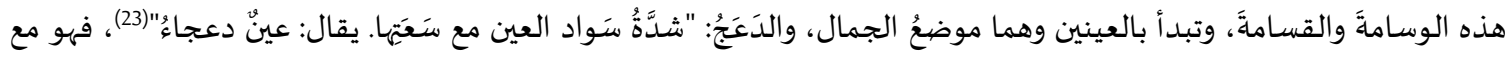




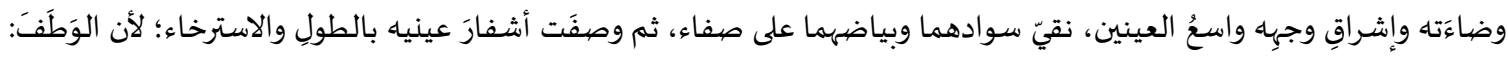

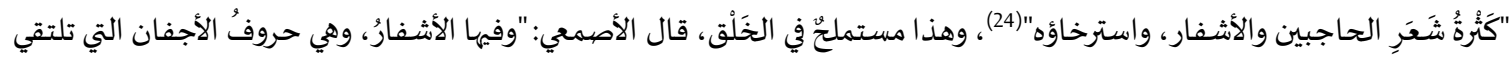

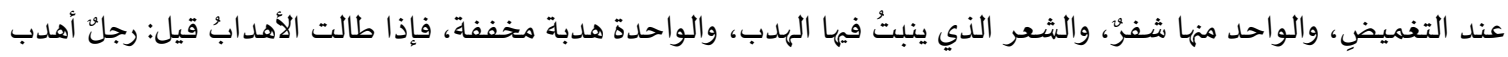

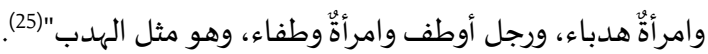

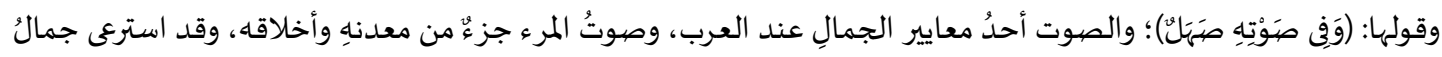

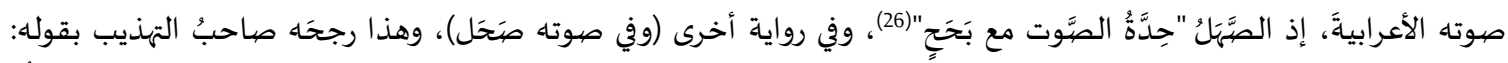

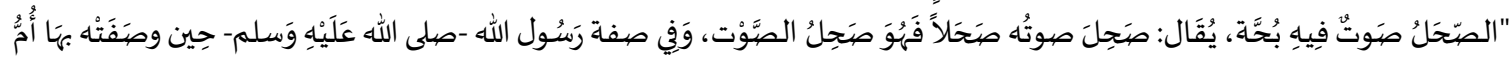

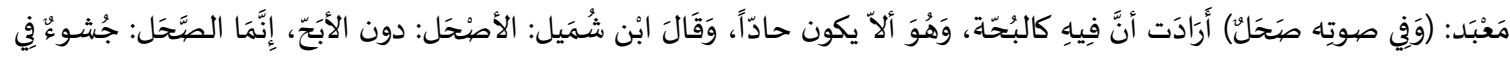

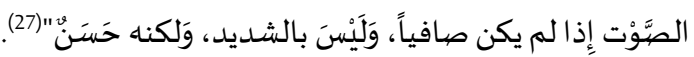

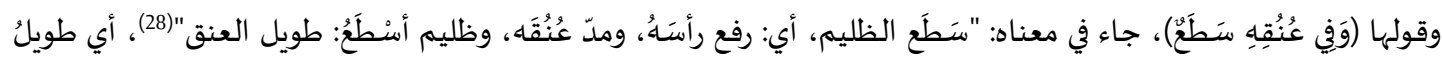

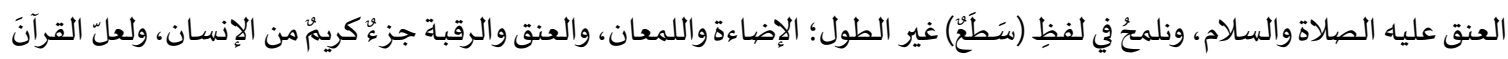

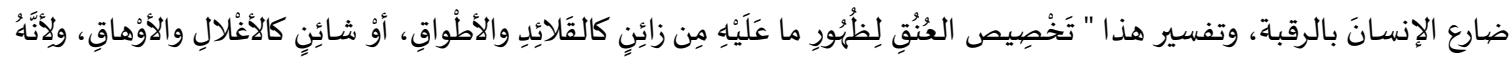

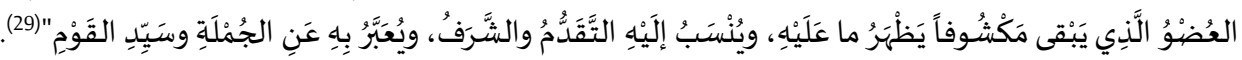

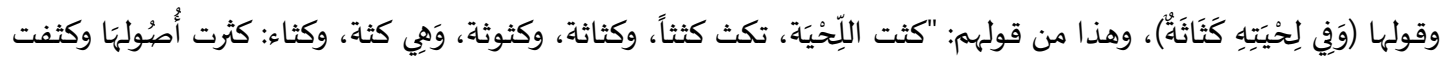

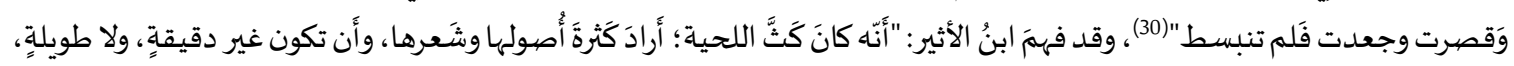
وفيها كَثافة" (31). وهذا أجملُ للحيةِ وأكمل، وكانت العربُ تعيب بخفة شعرِ اللحية، حتى أطلقوا على خفيفِ شعرِ اللحية "رجل أضرَرَطُ: خَفِيف اللِّحَيَة قليلها"(32).

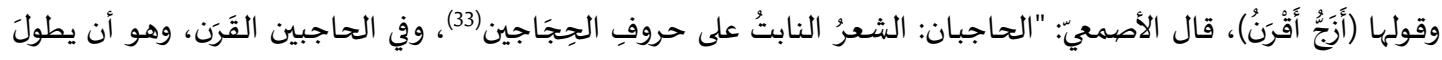

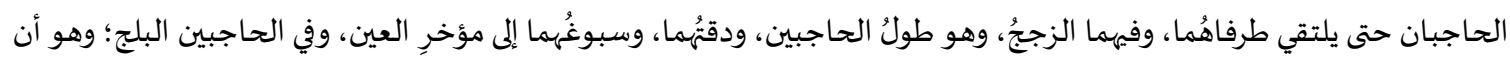

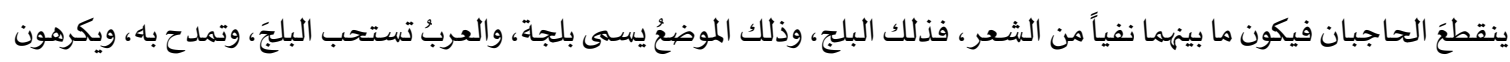
الغمم، يقالُ رجل أبلج وامرأة بلجاء" (34).

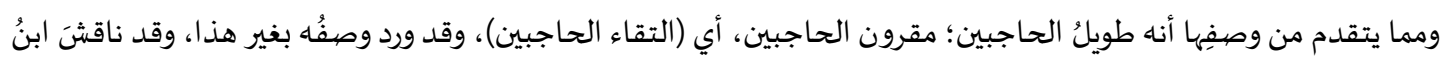

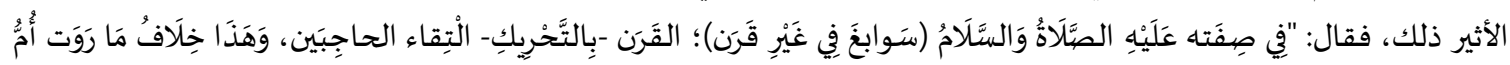

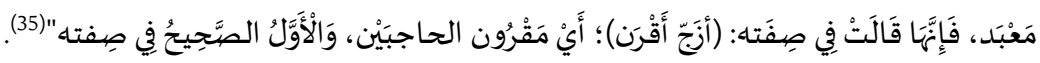

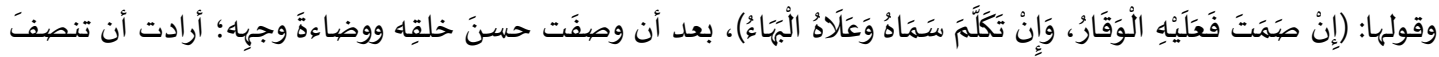

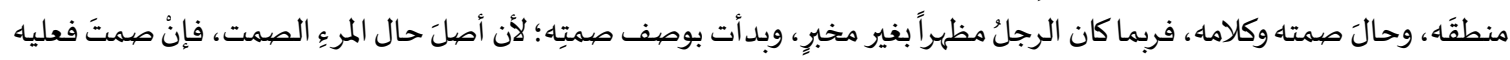

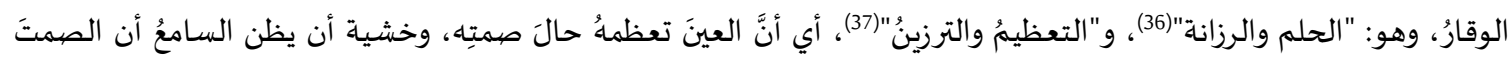

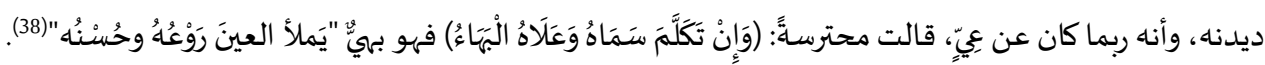

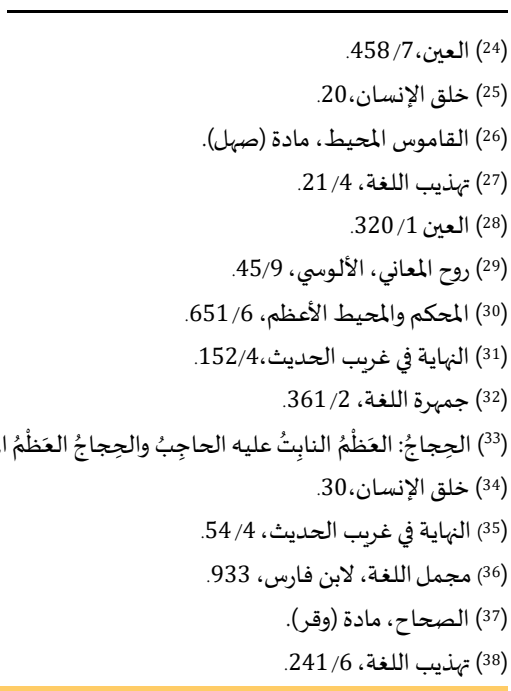




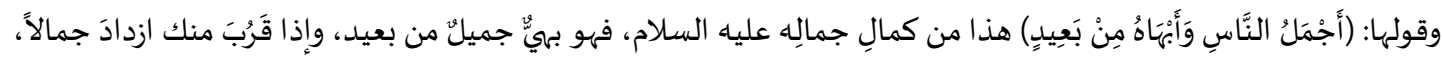

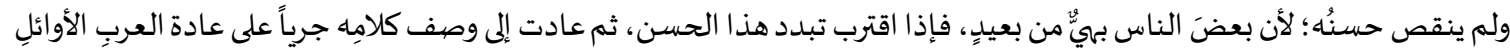

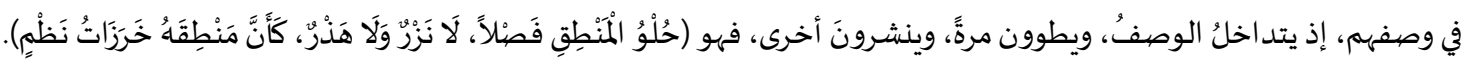

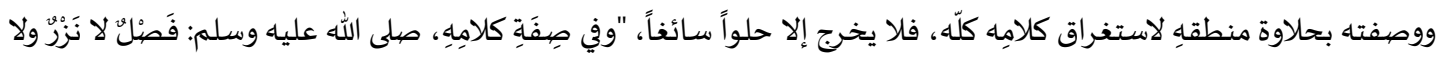

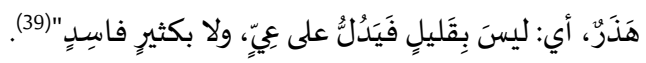
وقد مدحت العربُ بهذا، قَالَ ذُو الرُرََّّة:

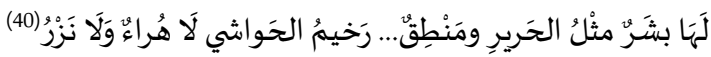

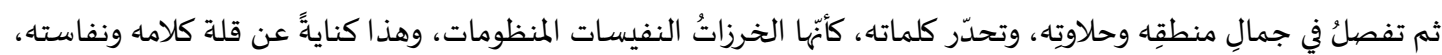

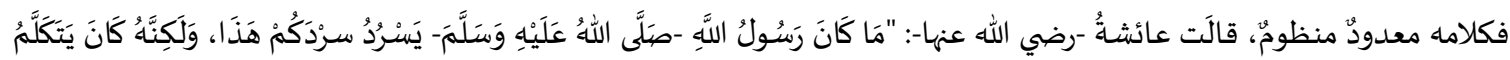

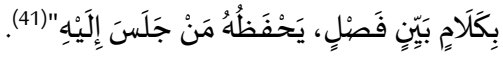

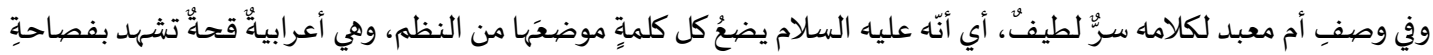

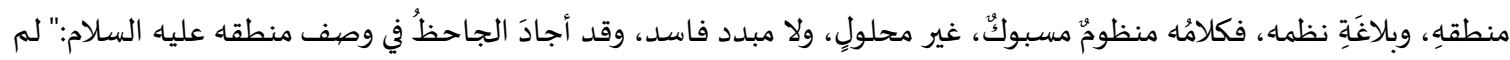

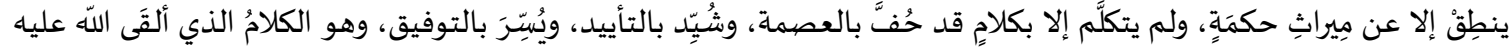

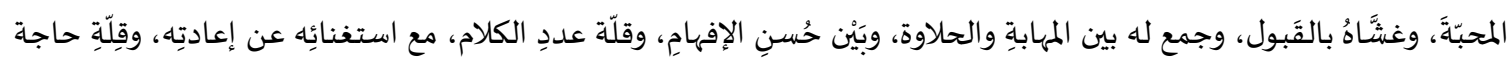

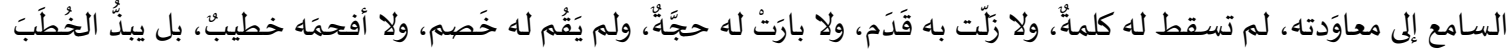

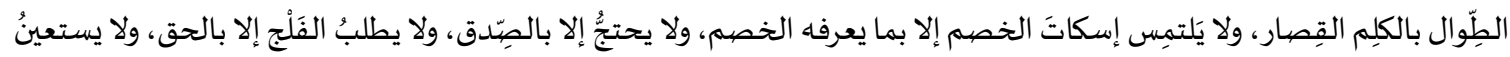

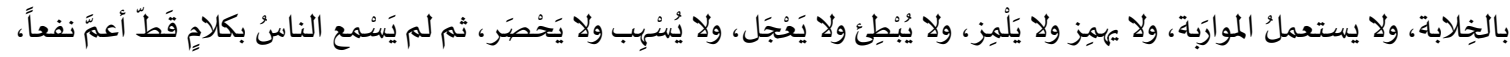

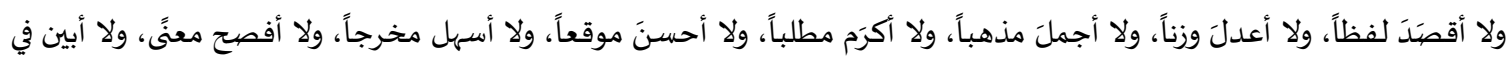

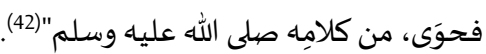

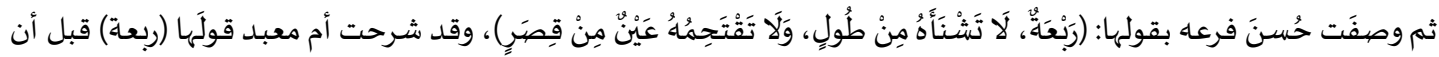

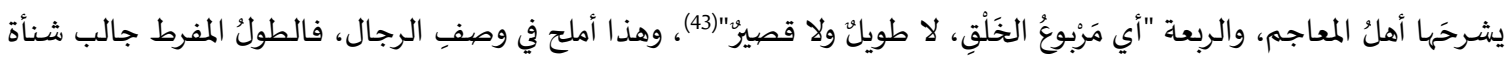

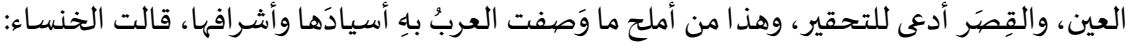

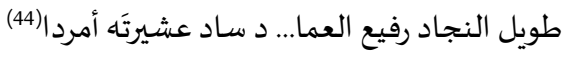

وقال المبرد معقباً على قولها، "قولها: طويل النجاد، النجاد: حمائل السيف، تريد بطول نجاده طول قامته، وهذا مما يُمد حُح به الشريف"(45).

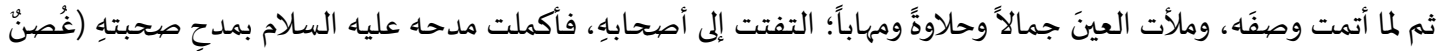

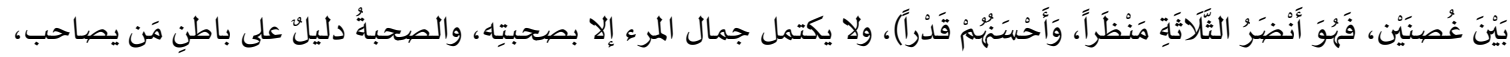

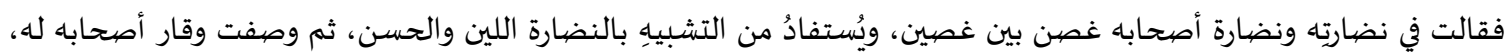

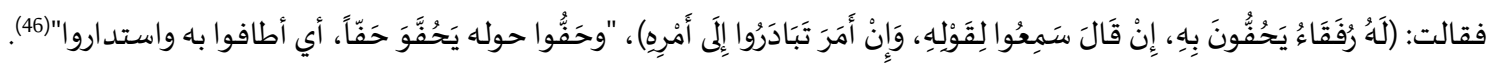

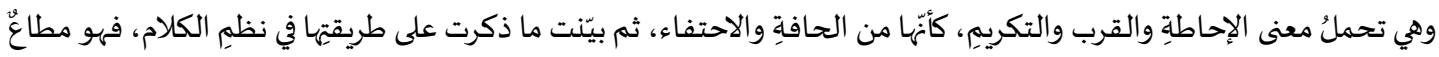

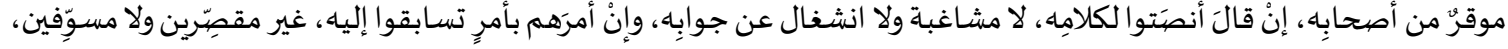

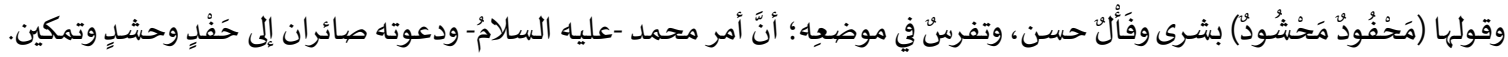




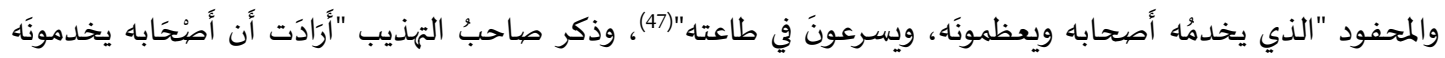

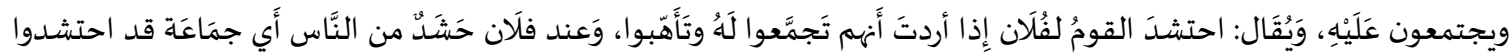

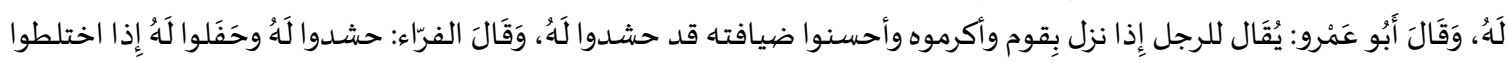

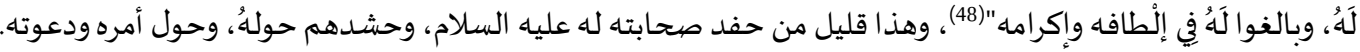

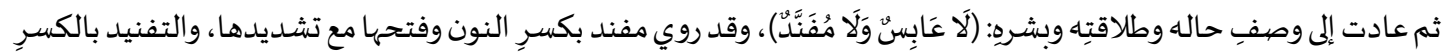

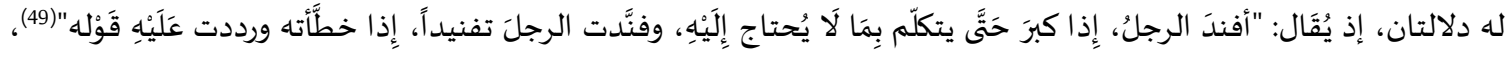

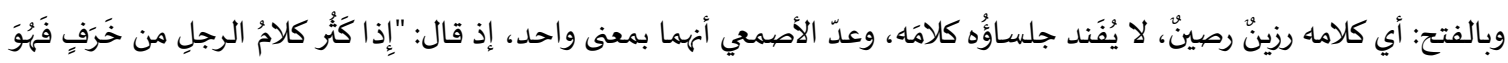

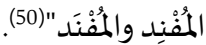

وهذا من أدبٍ النبوة العالي، فهو ليس بعابسٍ، ولا لجوج صَخوب، بل منصتُّ لهم، موقرٌ لحديثهم، وهم موقرون له، معظمون

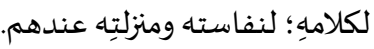
إذا تأملتَ أوصافَ الأعرابية وجدَّها عزيزةً نفيسةً مليحةًَ، مشرقةً بأنوار النبوة وجمالها وملاحتها، حتى نتذكرَ قولَ حسان رضي الله

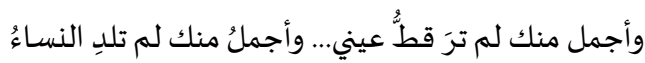

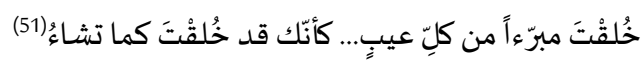

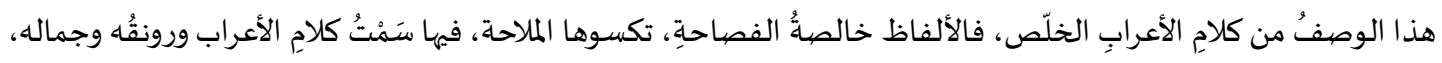

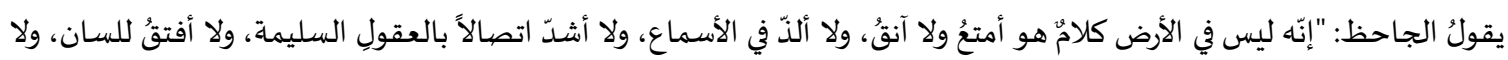

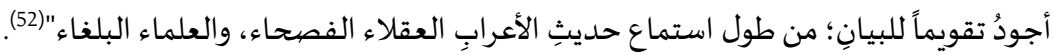

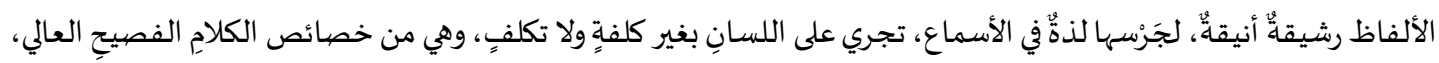

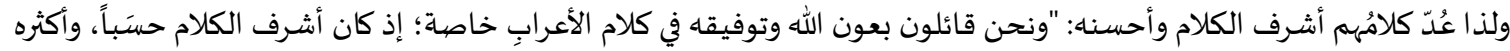

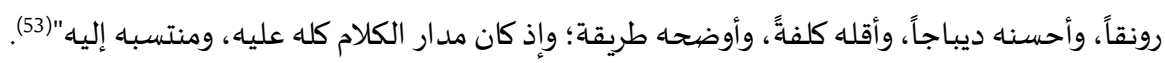

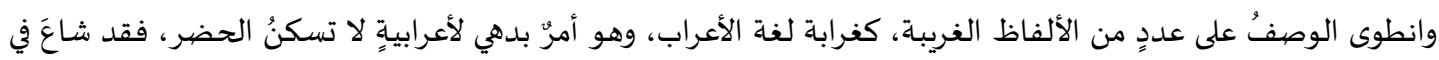

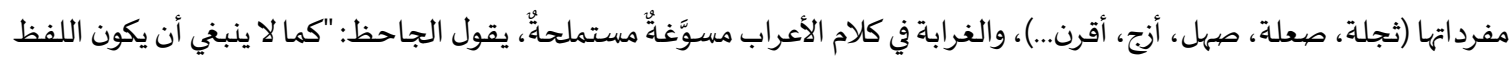

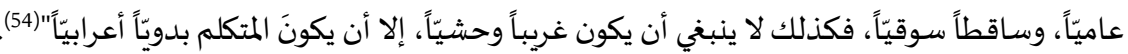

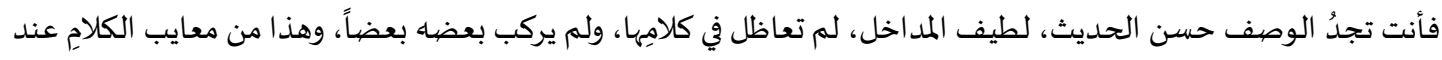

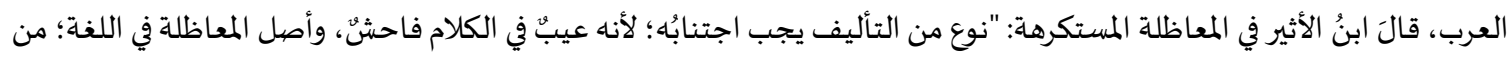

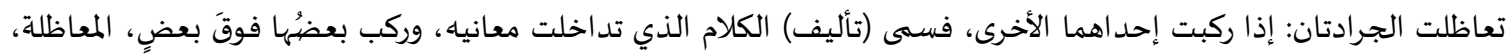

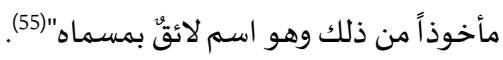

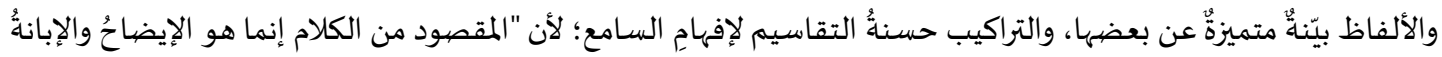

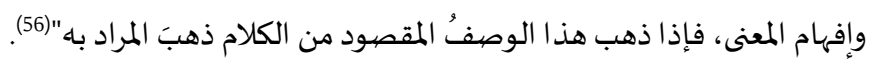

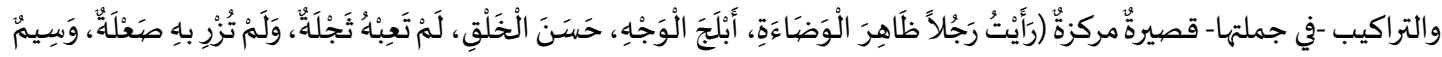

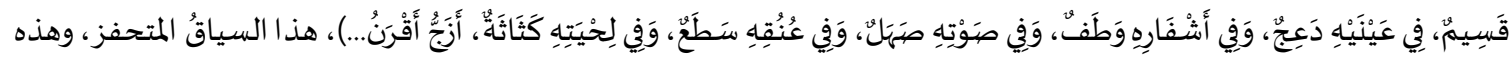

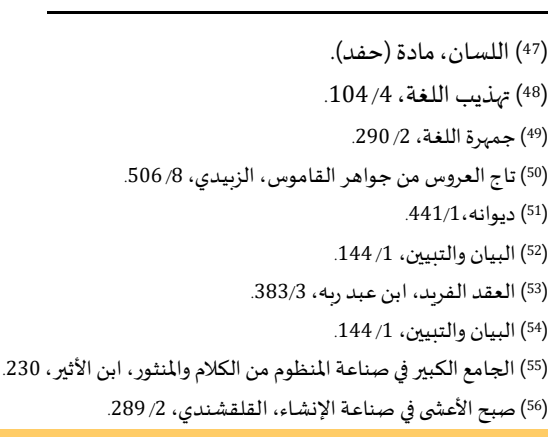




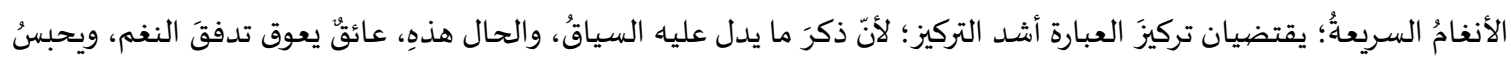

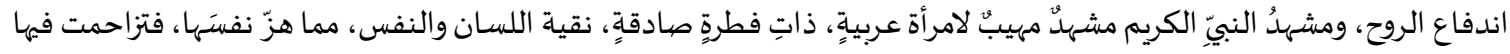

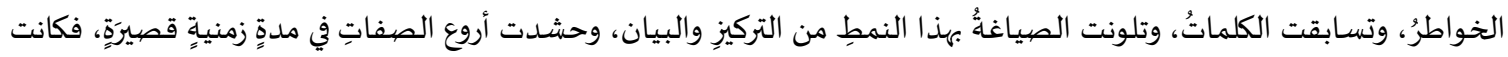

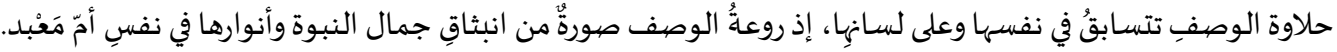

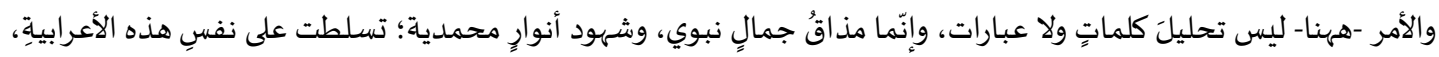
فأخرجت أجملَ ما في نفسها، وآنقَ ما في بيان الأعراب.

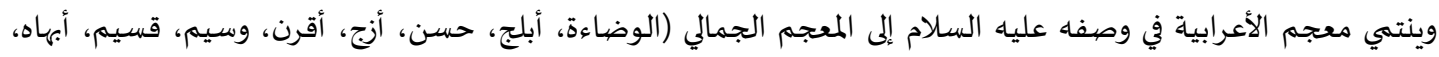

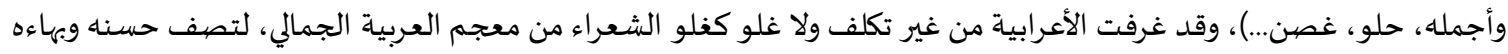

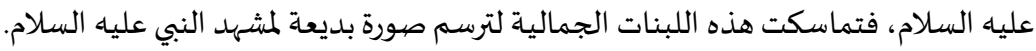

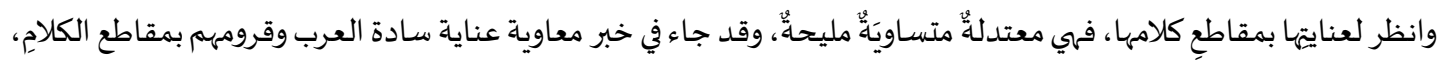

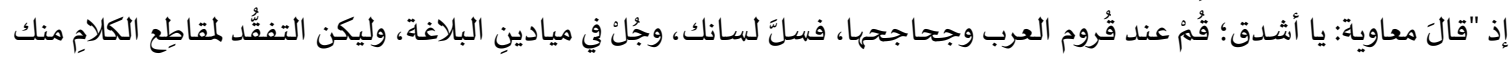

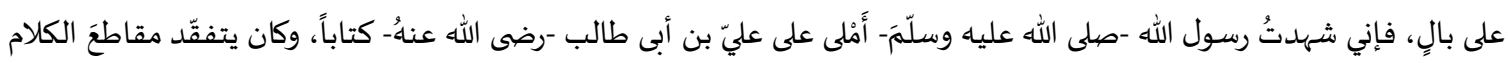

كتفقد المُصرّم صريمتهه" (57).

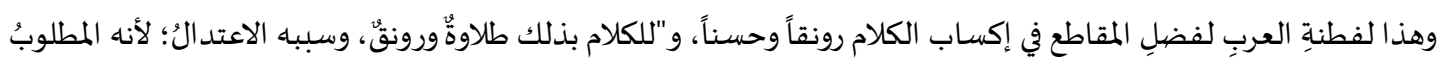

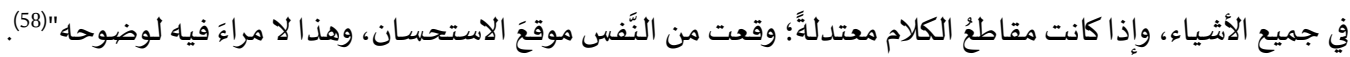

المبحث الثالث: بلاغَة الوصف

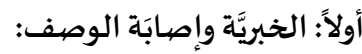

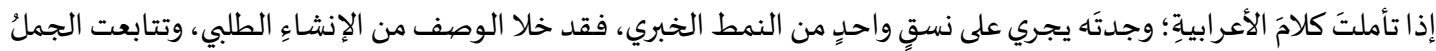

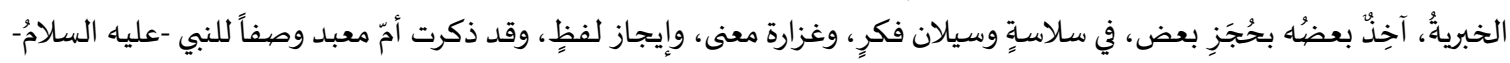

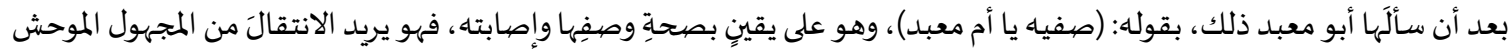

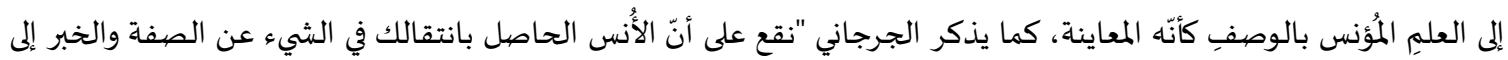

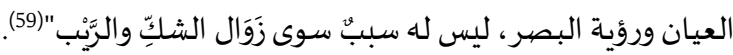

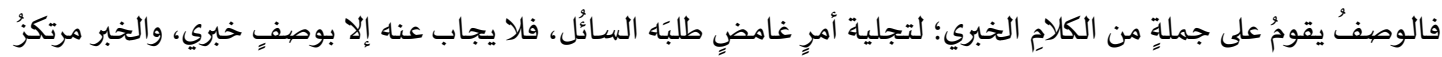

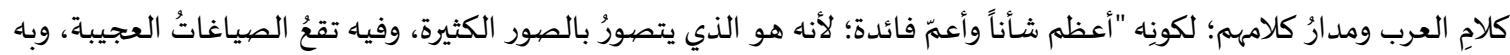

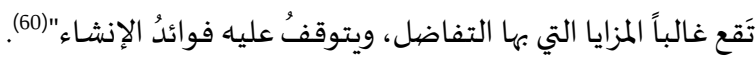

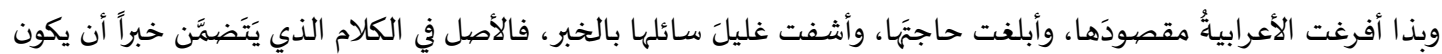

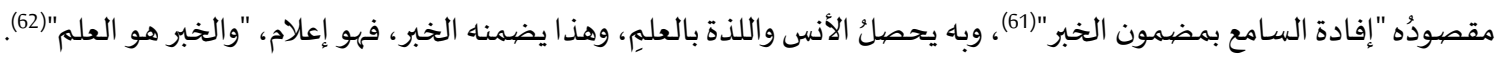

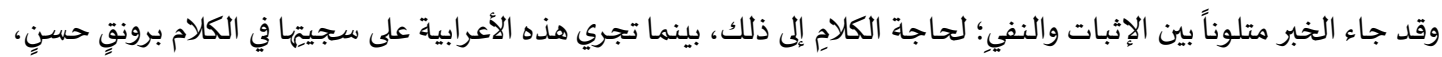

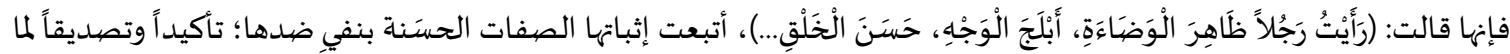

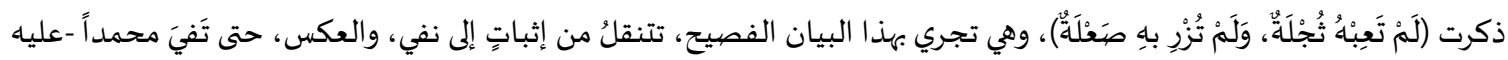

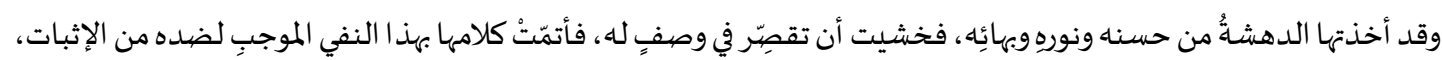

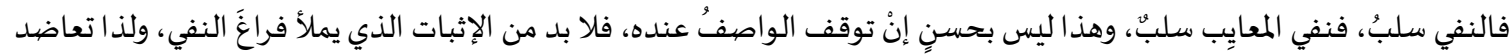

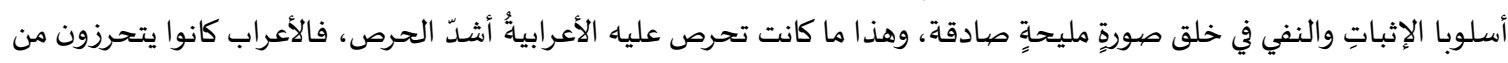

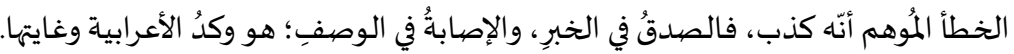

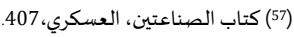

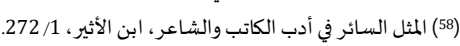

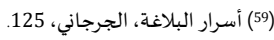

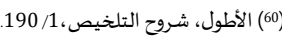

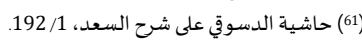

(62) الصاحبي في فقه اللغة، ابن فارس، 179. 


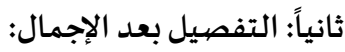

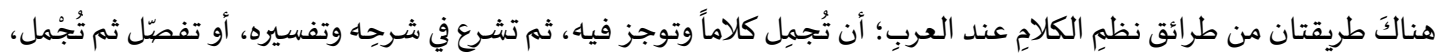

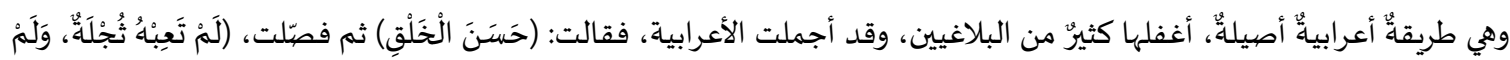

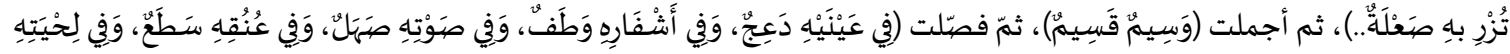

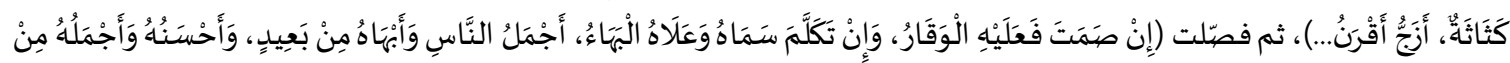

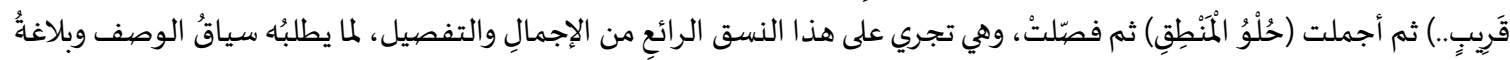

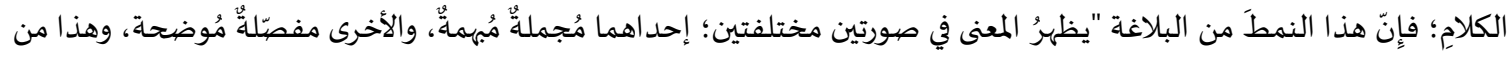

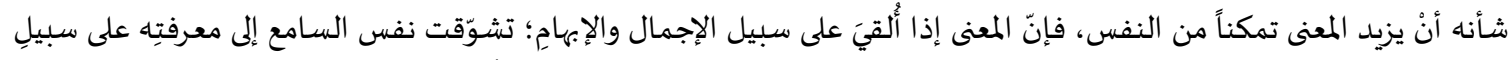

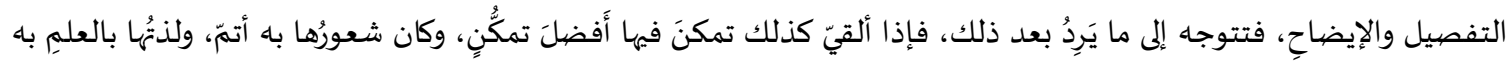

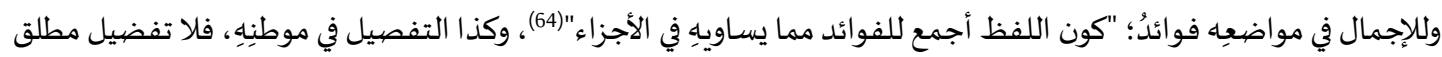

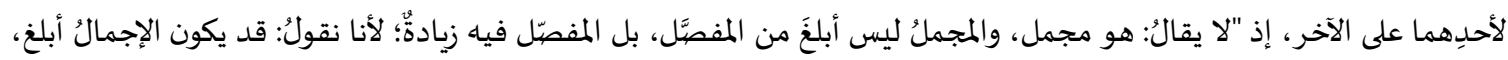

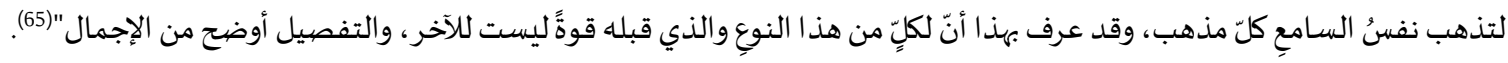

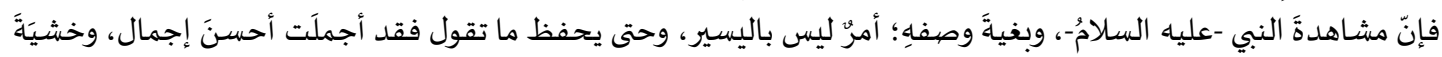

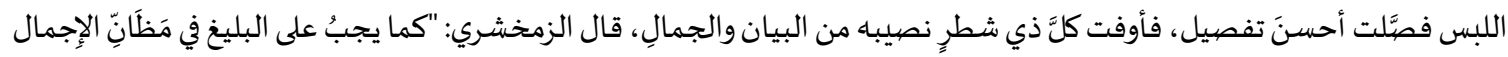

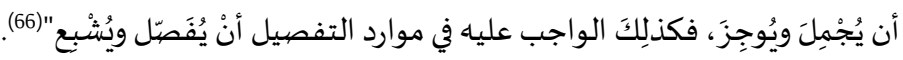

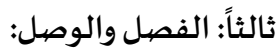

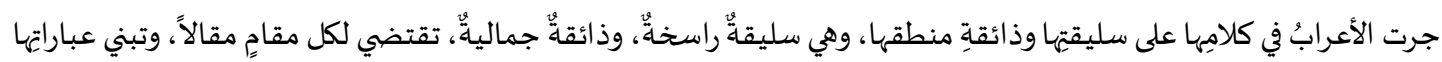

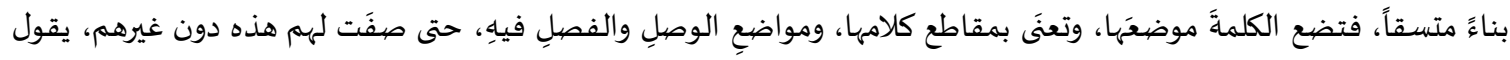

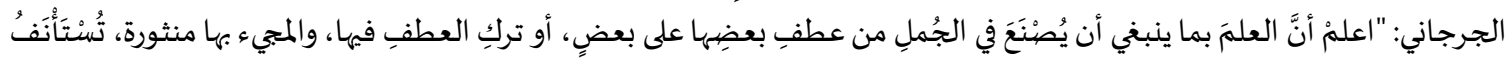

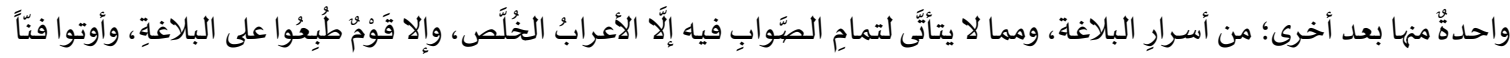

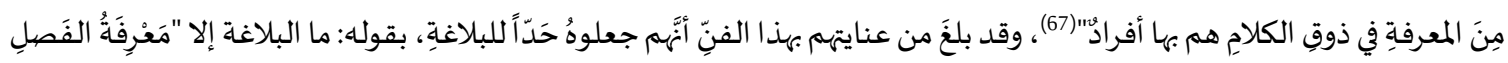
منَ الوصلِ" (68).

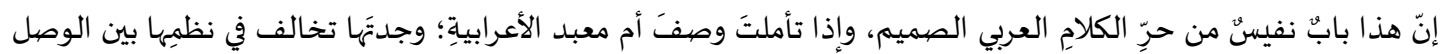

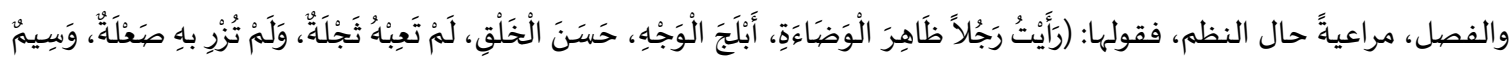

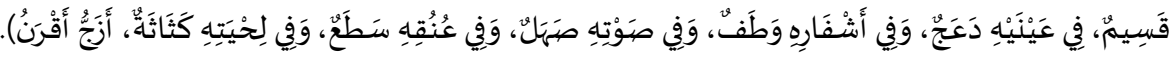

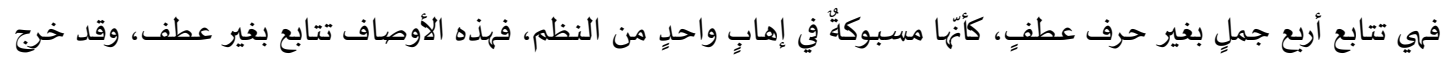

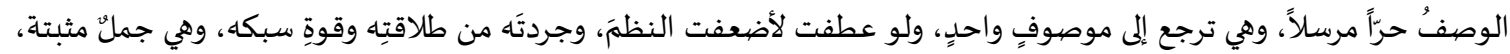

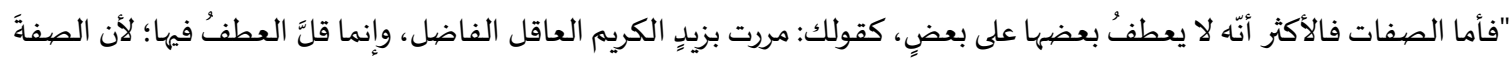

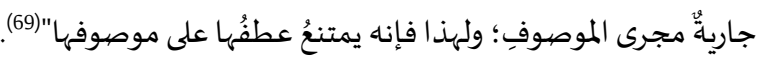

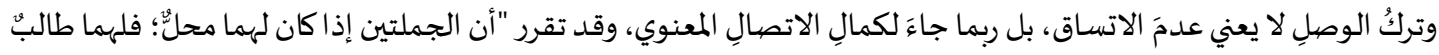

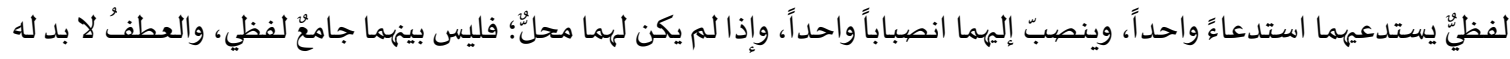

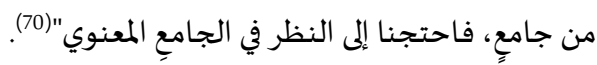

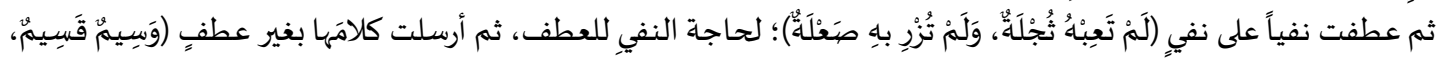

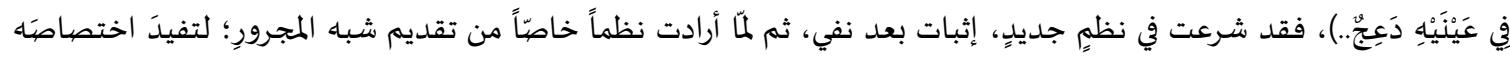

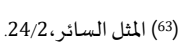

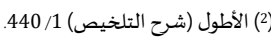

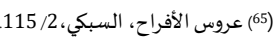
(66) أنوار الربيع في أنواع البديع، صدر الافر الديكي، الدين المدني،22/6.

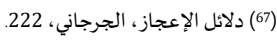

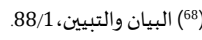

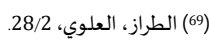

(70) عروس الأفراح، السبكي، العري، 125. 


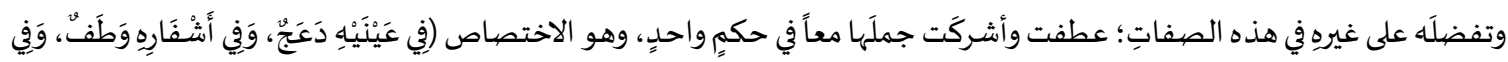

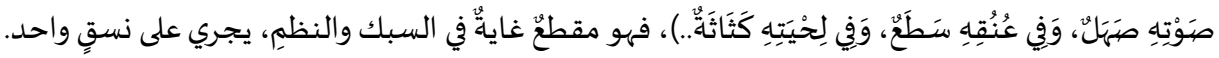

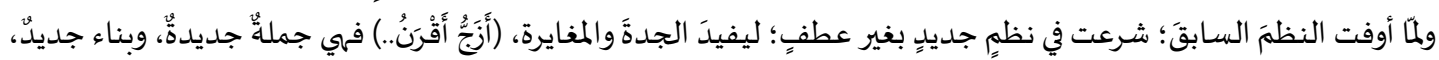

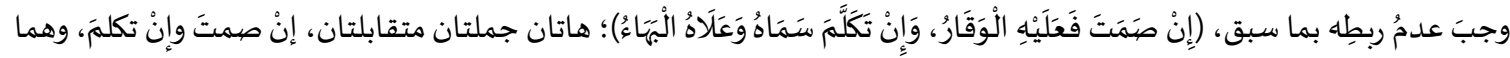

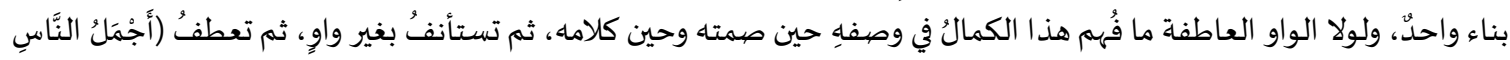

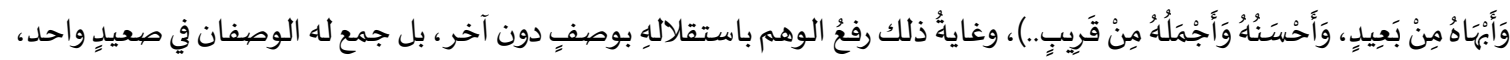

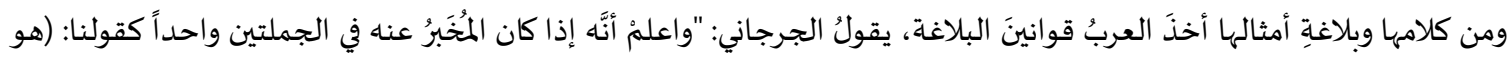

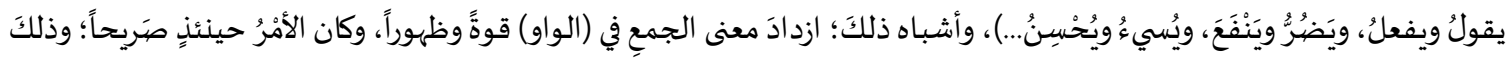

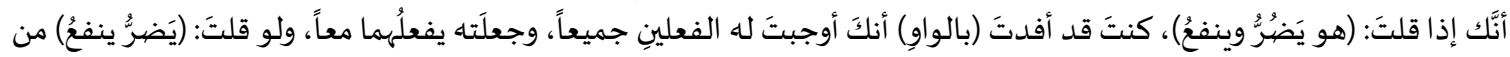

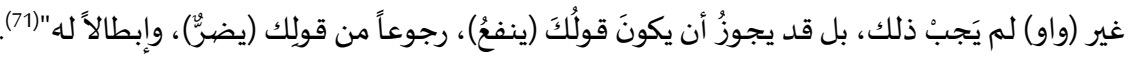

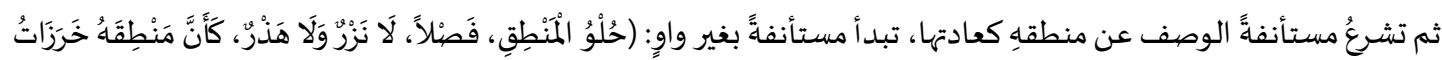

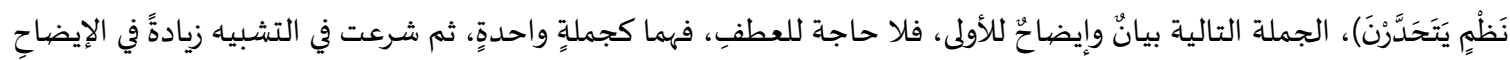

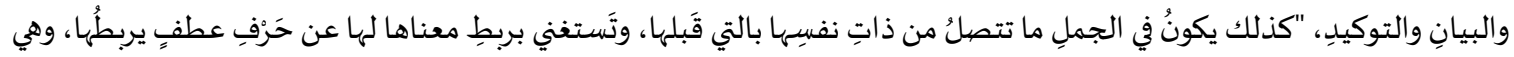

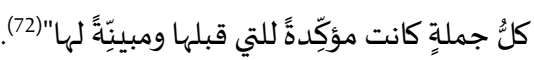

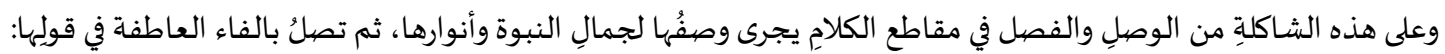

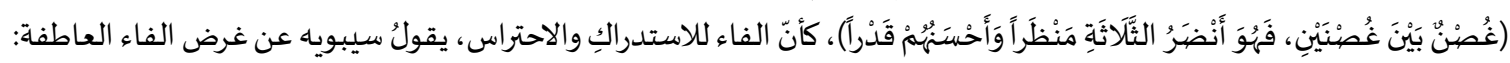

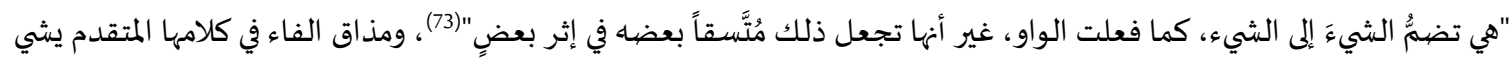
بالاحتراس والاستدراك، وهو باب نفيس من أبواب البلاغة كمانة والبيان.

\section{المبحث الر ابع: الإيقاع الصيوتي}

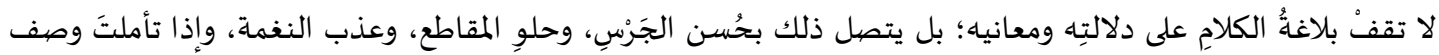

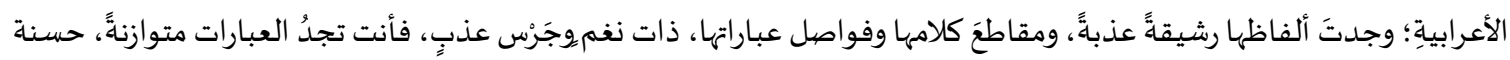

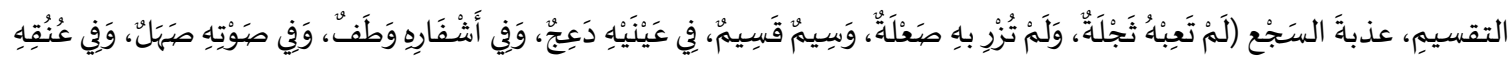

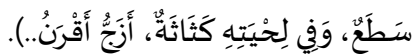

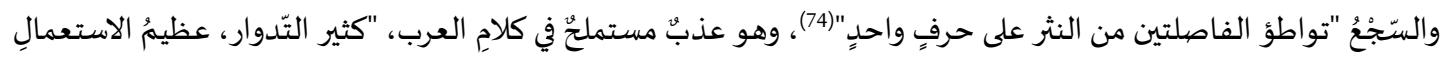

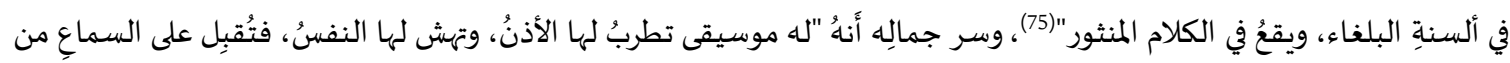

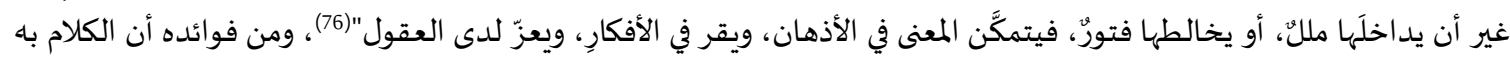

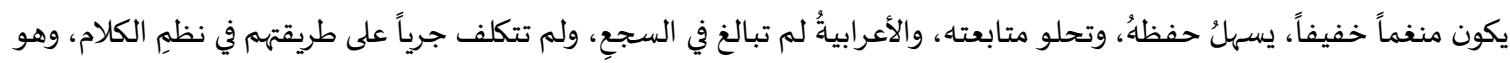

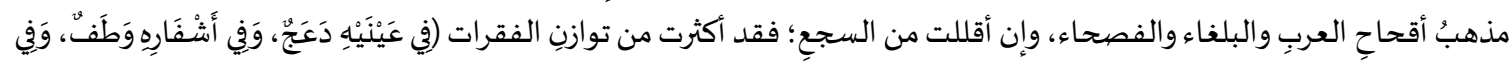

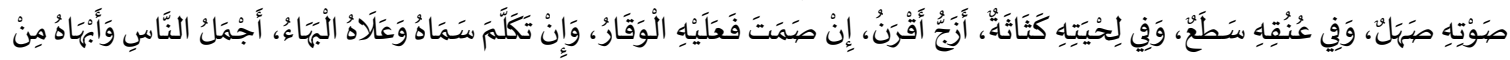

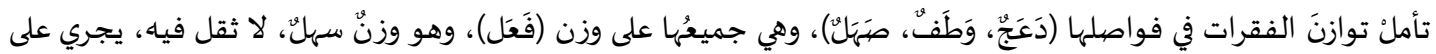

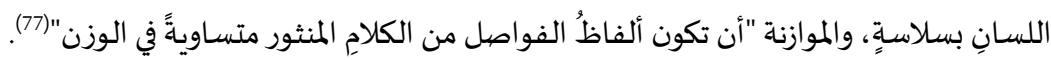

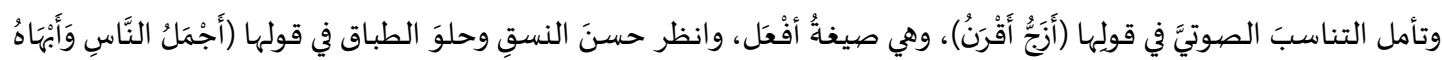

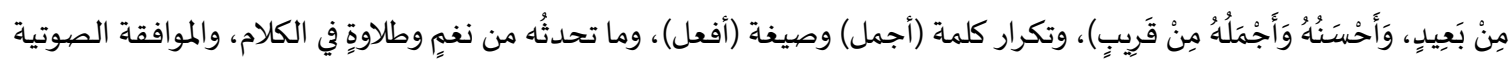

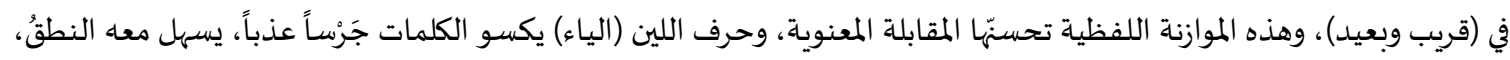




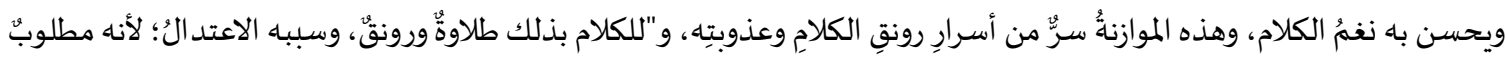

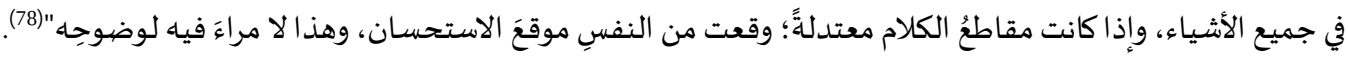

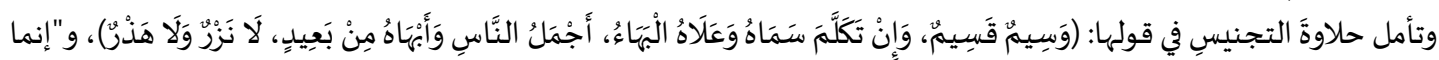

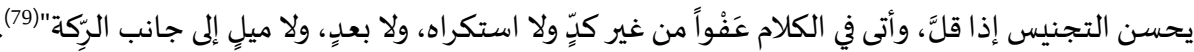

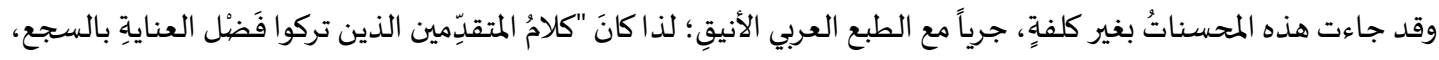

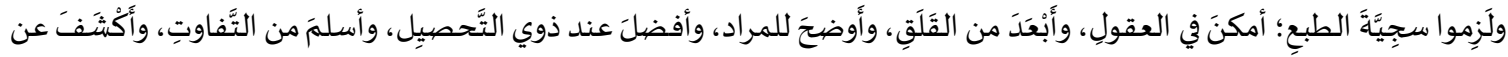

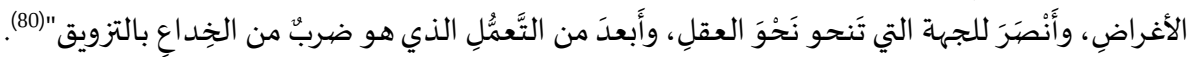

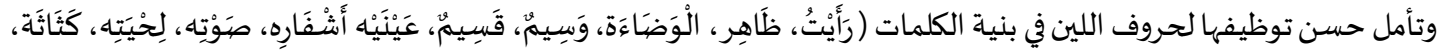

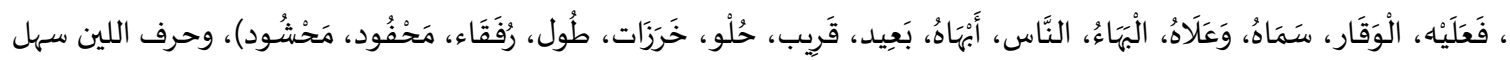

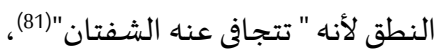

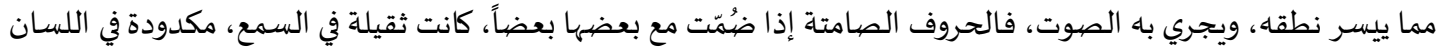

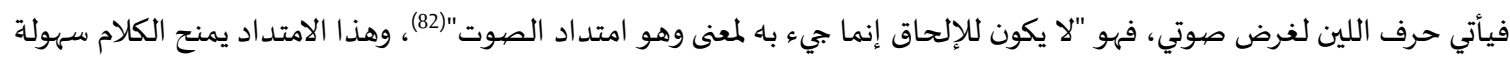

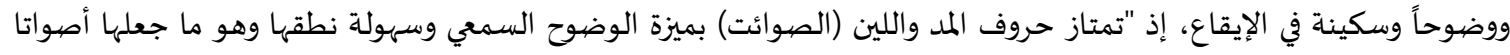

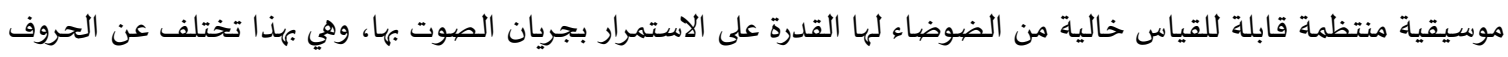
الساكنة الصحيحة (الصوامت) التي هي عبارة عن ضوضاء ناتية التهة عن الاحتكاك" (83).

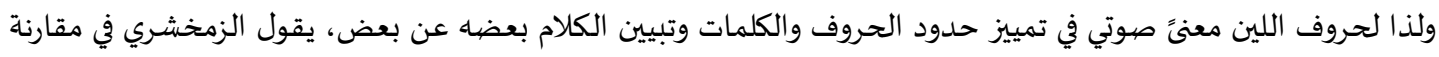

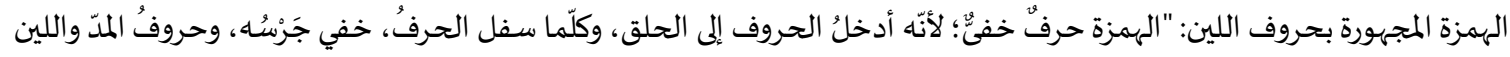

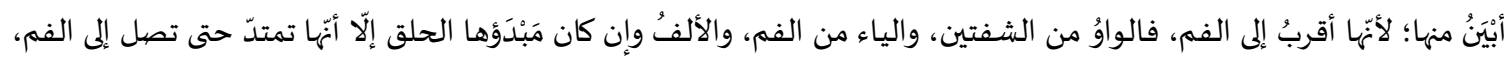

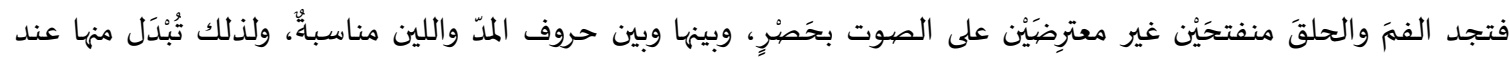
التخفيف"(84). والأعرابية بسليقها الصافية اهتدت إلى هذا النغم المطرب في حروف اللين، ليسهل عليها النطق، وليطرب السامع بمقاطع كلامها،

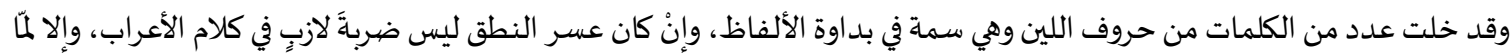

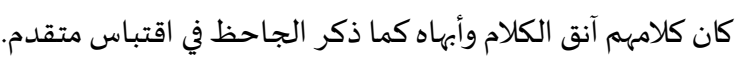

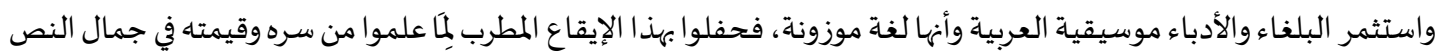

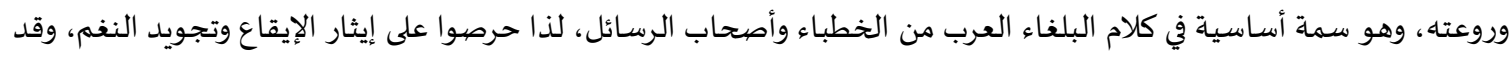

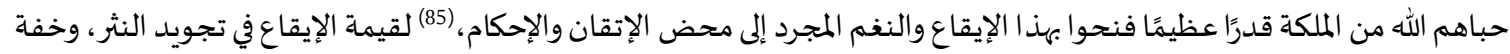
مؤونته على الأسماع والقلوب.

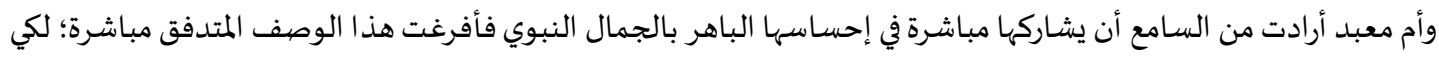

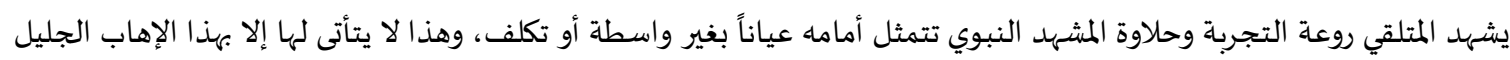
الجميل من الإيقاع العَذَبِ المُطُرب. 


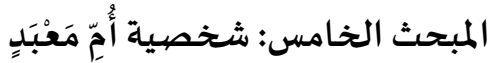

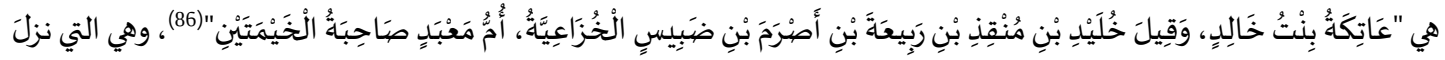

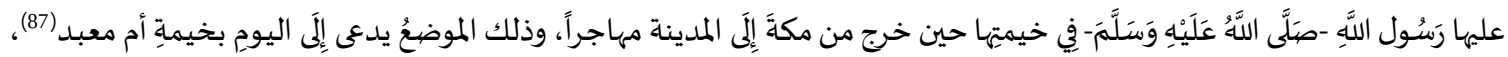

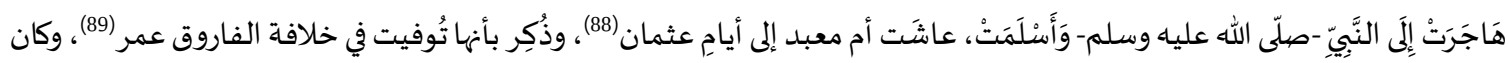

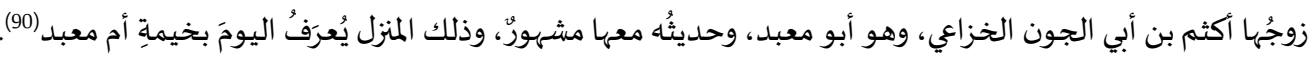

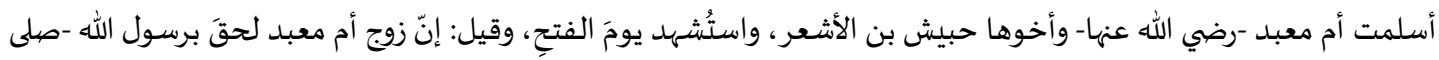

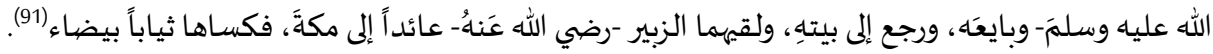

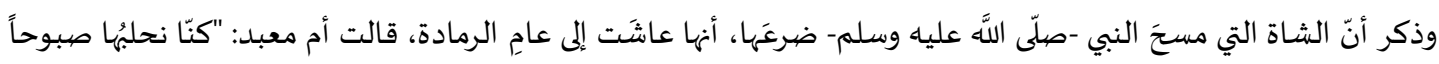
وغبوقاً، وما في الأرض لبن قليلُ ولا كثير "(92).

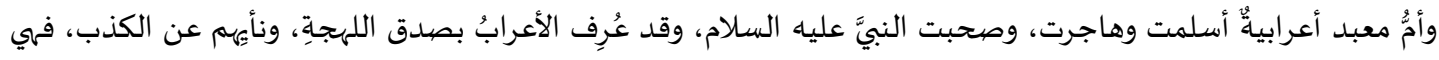
صادقةٌ موثوقةٌ فيما تروي.

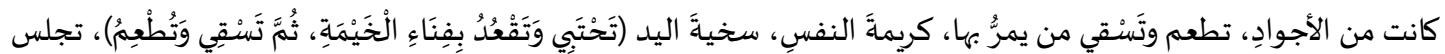

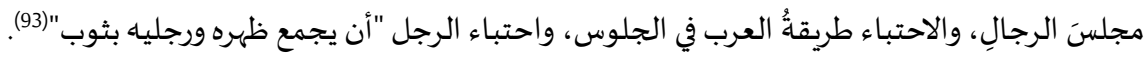

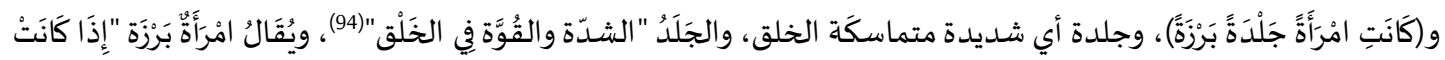

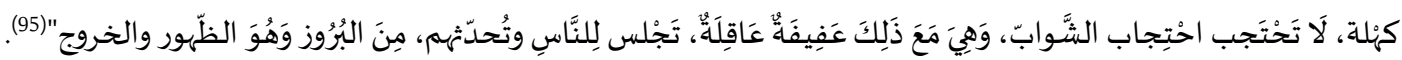

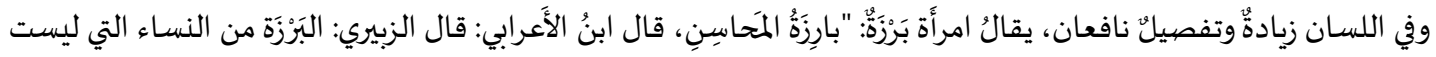

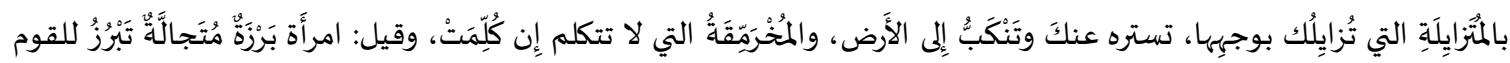

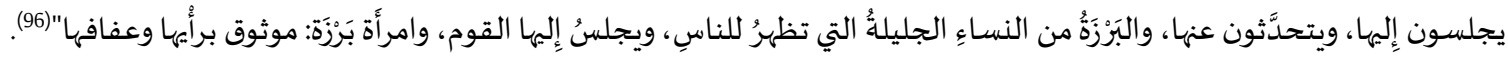

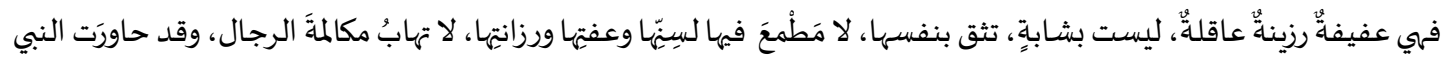

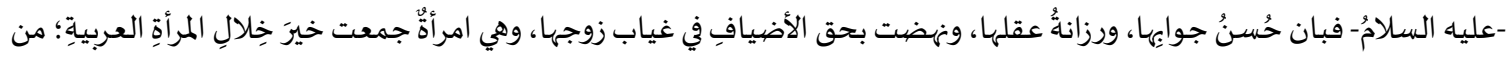

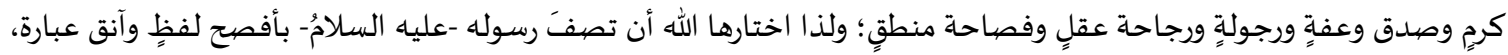

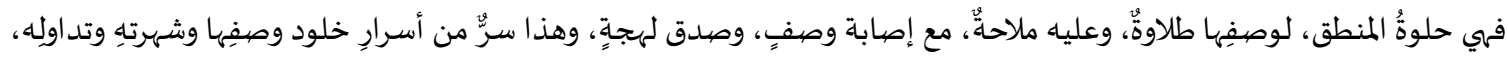
وعناية الرواة باء.

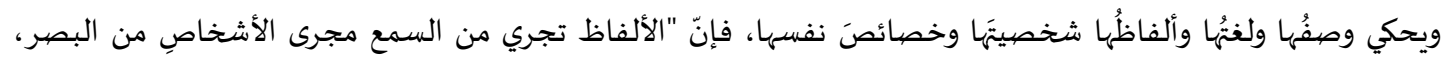

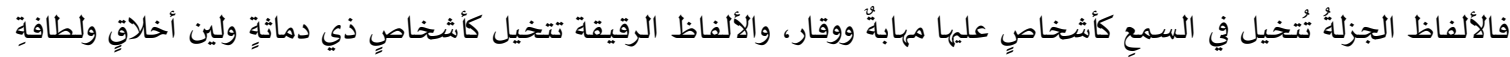

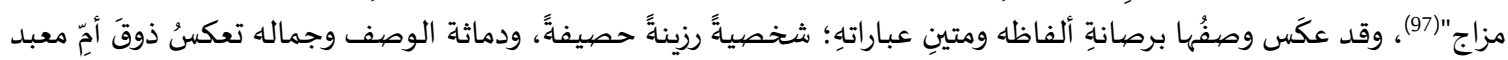

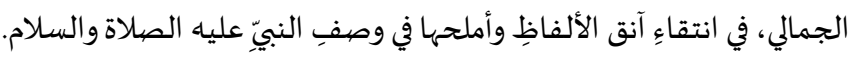

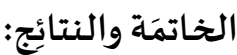

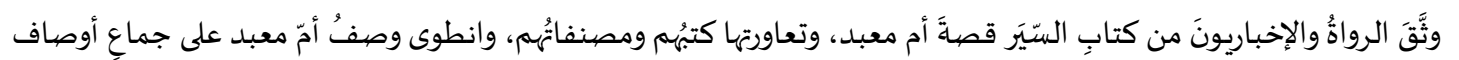

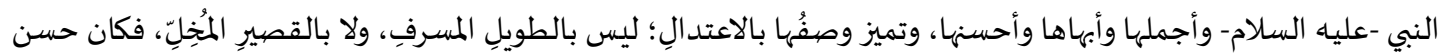




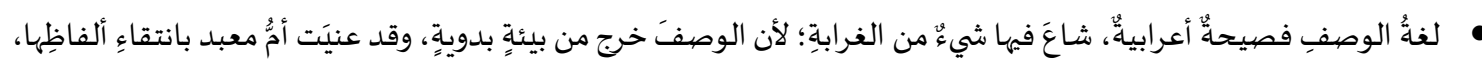

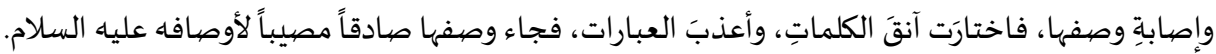

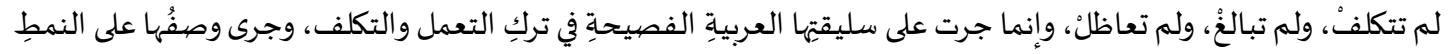
الخبري، وأحسنَت في بابٍ الوصلِ والفصلِ والتفصيلِ بعد الإجمالِ.

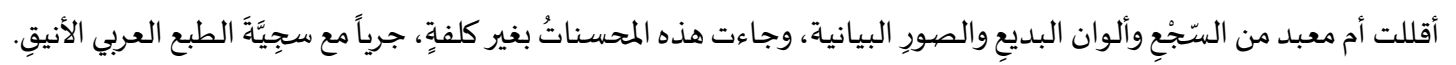

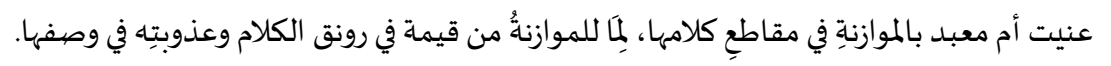

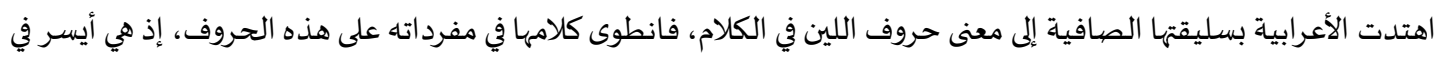

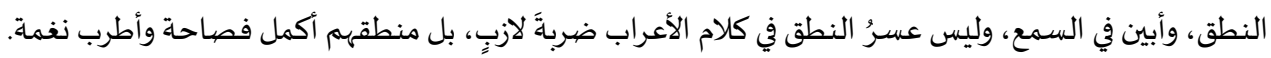

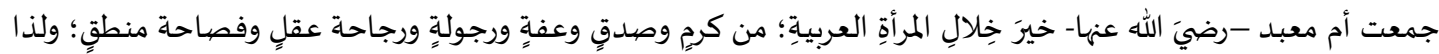

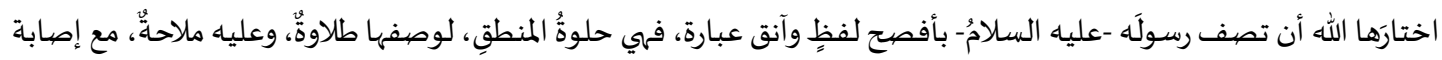
وصفٍ، وصدق لهجةٍ، وهذا سر من أسرار خلودِ وصفها، وشهرتِه، وتداولِّه، وعناية الرواةِ به.

المراجع:

1. ابن الأثير، أبو السعادات المبارك الشيباني، النهاية في غريب الحديث والأثر، تحقيق: طاهر الزاوي، محمود الطناحي، السعودية،

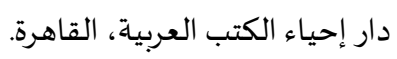
2. ابن الأثير، ضياء الدين (1956). الجامع الكبير في صناعة المنظوم من الكلام والمثنثور، تحقيق: مصطفى جواد، جميل سعيد، مطبعة المجمع العلمي، العراق. 3. ابن الأثير، ضياء الدين (1995). المثل السائرفي أدب الكاتب والشاعر، تحقيق: محمد محي الدين عبد الحميد، المكتبة العصرية،

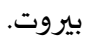
4. ابن الأثير، علي بن محمد (2003). أسد الغابة في معرفة الصحابة ، دار الفكر، بيروت. 5. 6. دار الكتب العلمية، بيروت، الطبعة الأولى.

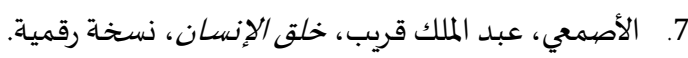
8. الألوسي، محمود شكري، روح المعاني في تفسير القران العظيمر والسبع المثاني، قرأه وصححها: محمد حسن العرب، دار الفكر، بيروت. 9. الترمذي، محمد بن عيسى (1999). الجامع الصحيح (سنن التومني)، تحقيق: أحمد محمد شاكر ، مصطفى محمد حسين الذهبي، دار الحديث، القاهرة.

10. الترمذي، محمد بن عيسى (2005). الشَمائل المحمدلية، تحقيق: سيد عمران، دار الحديث، القاهرة، الطبعة الأولى.

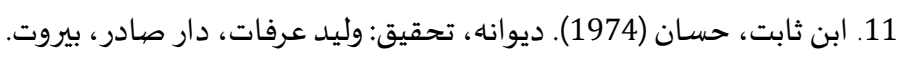

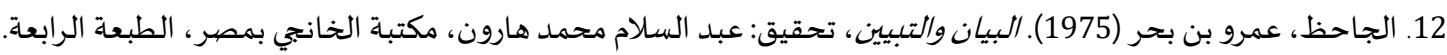

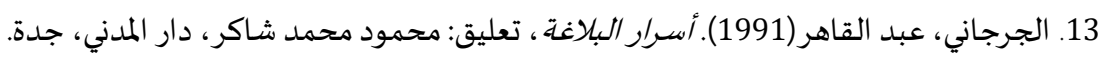
14. ابن جني، عثمان سعد (1986). الخصبائص، الخبل تحقيق: محمد على النجار، الهيئة المصرية العامة للكتاب، القاهرة.

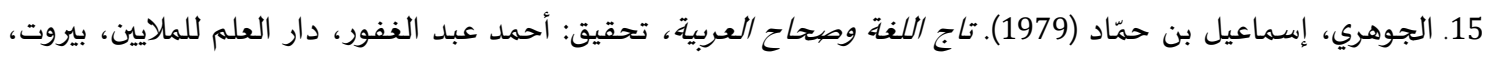
الطبعة الثانية.

16. الحسيني، صدر الدين (1968). أنوار الربيع في أنواع البديع، تحقيق: شاكر هادي شاكر، مطبعة النعمان، النجف الأشرف. 17. الخطابي، أحمد بن محمد بن إبراهيم (1983). غريب الحـديث، تحقيق: عبد الكريم إبراهيم العزباوي، دار الفكر، دمشقي.

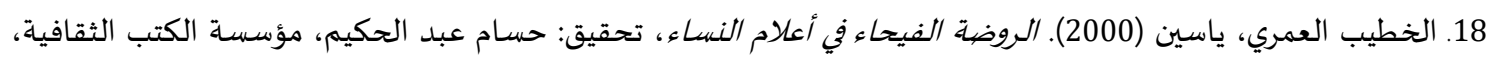
بيروت، الطبعة الأولى.

19. الخنساء، تماضر، ديوانها ، شرحه وضبطها: عمر الطباع، دار الأرقم، بيروت.

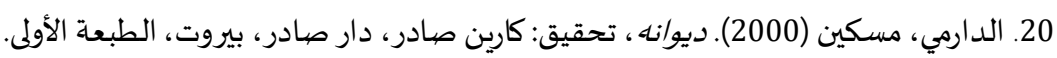


21. ابن دريد، محمد بن الحسن:جمهرة اللغة ، دار صهادر، بيروت.

22. ذو الرما، غيلان بن عقبة (1998). ديو/نه، ،حقيق:عمر الطباع، دار الأرقم بن أبي الأرقم، بيروت، الطبعة الأولى.

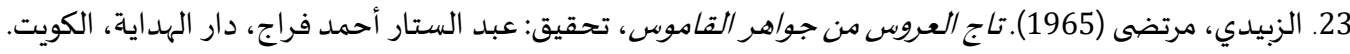
24. ابن زكريا القزويني، أحمد بن فارس (1986). مجمل اللغة ، تحقيق: زهير عبد المحسن سلطان، مؤسسة الرسالة، بيروت، الطبعة الثانية.

25. الزهري، محمد بن سعيد (2001).كتاب الطبقات الكبير، تحقيق:علي محمد عمر، مكتبة الخانجي، القاهرة، الطبعة الأولى. 26. السبكي، بهاء الدين أحمد بن علي بن عبد الكافي (2003). عروس الأفراح في شرح تلخيص المفتاح، تحقيق: عبد الحميد هنداوي، المكتبة العصرية، بيروت، الطبعة الأولى.

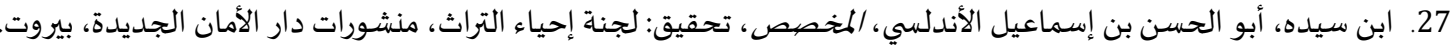

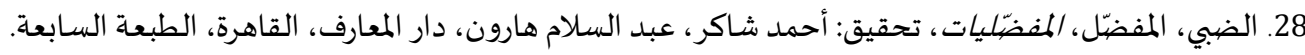
29. الطيب، عبد الله (1991). المرشد إلى فهم أشعار العرب وصناعتها ، دار جامعة الخرطوم، السودان، الطبعة الثالثة.

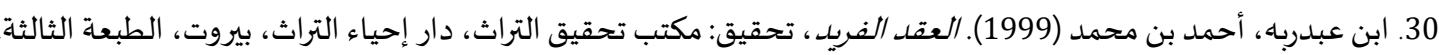

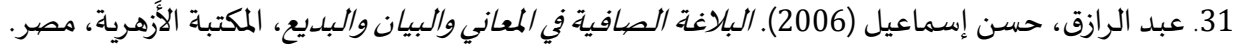
32. العسكري، أبو هلال (2006).كتاب الصناعتين: الكتابة والشعر، تحقيق:علي البجاوي، محمد إبراهيم، المكتبة العصرية، بيروت، الطبعة الأولى.

33. العلوي، يحيى بن حمزة (2010). الطراز: المتضيمن لأسرار البلاغة وعلوم حقائق الإعجاز، تحقيق: الشربيني شريدة، دار الحديث، القاهرة. 34. ابن فارس، أبو الحسن أحمد (1993). الصياحبي في فقه اللغة العببية ومسائلها وسنن العرب في كلامها، تحقيق: عمر فاروق الطباع، مكتبة المعارف، بيروت

35. ابن فارس القزويني، أحمد(1991). معجمر مقاييس اللغة، تحقيق: عبد السلام محمد هارون، دار الجيل، بيروت.

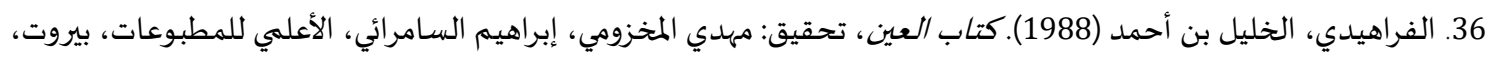
الطبعة الأولى.

37. الفيروز آبادي، مجد الدين (2008): القاموس المحيط، راجعه، ، أنس الشامي، زكريا أحمد، دار الحديث، القاهرة.

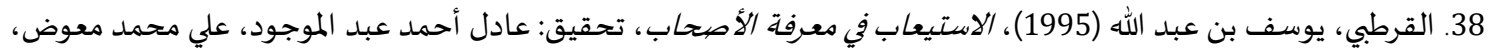
دار الكتب العلمية، بيروت.

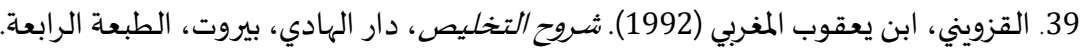

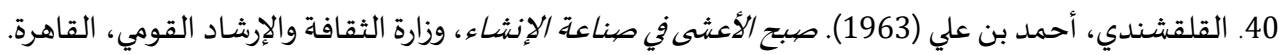

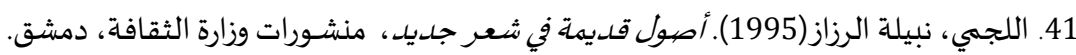

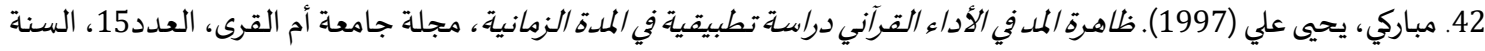
العاشـرة.

43. المبرد، محمد بن يزيد (1986). الكامل، تحقيق: محمد أحمد الد الي، مؤسسة الرسالة، بيروت، الطبعة الأولى.

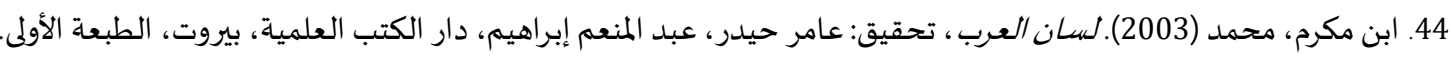
45. النويري، أحمد بن عبد الوهاب، نهاية الأرب في فنون الأدب، وزارة الثقافة والإرشاد القومي، مصر. 46. النيسابوري، الحاكم (2002). المستدرك على الصحيحين، تحقيق: مصطفى عبد القادر أحمد عطا، دار الكتب العلمياة، بيروت، الطبعة الثانية. 47. ابن يزيد القزويني، أبو عبد الله محمد (1997). صححيح سنن /بن ماجه ، جمع: محمد ناصر الدين الألباني، مكتبة المعارف، الرياض. 48. ابن يعيش، يعيش (2001). شرح المفصّل للزمخشري، تقديم: إميل بديع يعقوب، دار الكتب العلمية، بيروت، الطبعة الأولى. 
المجلة الدولية للدراسات اللغوية والأدبية العربية

International Journal for Arabic Linguistics and Literature Studies (JALLS)

www.refaad.com

Journal Homepage: https://www.refaad.com/views/JALS/home.aspx ISSN : 2663-5860(Online) 2663-5852(Print)

\section{Description rhetoric in Umm Ma'bad's language}

Walid. M. N. Abu. Nada

Professor at the Faculty of Arts, Department of Arabic Language, Islamic University - Gaza, Palestine wnada@iugaza.edu.ps

Received : 10/5/2021 Revised : 20/6/2021 Accepted : 7/8/2021 DOI : https://doi.org/10.31559/JALLS2021.3.3.1

Abstract: Hadith books and sources of the Prophet's biography discussed Umm Ma'bad Al Khuza'yya's

description of the Prophet (PBUH) when he was her guest during his migration from Mecca to Medina. Umm Ma'bad's description of the Prophet is one of the finest descriptions and is considered a significant literary genre in the literature of Arabic speech. The study highlighted the structural mysteries included in the description pointing out the Arab's early attempts in the formation of speech including its eloquence, nicely arranged structures and lexis, beauty of rhythm and the musical composition of structures. Al Khuza'yya's work was thoroughly done, especially that the person under description was Prophet Mohammed, the finest creature ever to be possessed with such highly distinguished personal features.

Keywords: Description; Rhetoric; Hadith; Umm Ma'bad.

\section{References:}

1. Altyb, 'bd Allh (1991). Almrshd Ela Fhm Ash'ar Al'rb Wsna'tha, Dar Jam't Alkhrtwm, Alswdan, Altb'h Althalthh.

2. Abn 'bdrbh, Ahmd Bn Mhmd (1999). Al'qd Alfryd, Thqyq: Mktb Thqyq Altrath, Dar Ehya' Altrath, Byrwt, Altb'h Althalthh.

3. Alalwsy, Mhmwd Shkry, Rwh Alm'any Fy Tfsyr Alqran Al'zym Walsb' Almthany, Qrah Wshhh: Mhmd Hsn Al'rb, Dar Alfkr, Byrwt.

4. Alasbhany, Ahmd Bn 'bd Allh (2002). M'rft Alshabh, Thqyq: Mhmd Hsn Mhmd Esma'yl, Ms'd 'bd Alhmyd Als'dny, Dar Alktb Al'lmyh, Byrwt, Altb'h Alawla.

5. Alasm'y, 'bd Almlk Qryb, Khlq Alensan, Nskhh Rqmyh.

6. Abn Alathyr, Abw Als'adat Almbark Alshybany, Alnhayh Fy Ghryb Alhdyth Walathr, Thqyq: Tahr Alzawy, Mhmwd Altnahy, Als'wdyh, Dar Ehya' Alktb Al'rbyh, Alqahrh.

7. Abn Alathyr, Dya' Aldyn (1956). Aljam' Alkbyr Fy Sna't Almnzwm Mn Alklam Walmnthwr, Thqyq: Mstfa Jwad, Jmyl S'yd, Mtb't Almjm' Al'Imy, Al'raq.

8. Abn Alathyr, Dya' Aldyn (1995). Almthl Alsa'r Fy Adb Alkatb Walsha'r, Thqyq: Mhmd Mhy Aldyn 'bd Alhmyd, Almktbh Al'sryh, Byrwt.

9. Abn Alathyr, 'ly Bn Mhmd(2003). Asd Alghabh Fy M'rft Alshabh, Dar Alfkr, Byrwt.

10. Alazhry, Mhmd Bn Ahmd (1964). Thdyb Allghh, Thqyq: 'bd Alslam Mhmd Harwn, Mhmd 'ly Alnjar, Aldar Almsryh, Alqahrh.

11. Aldarmy, Mskyn (2000). Dywanh, Thqyq: Karyn Sadr, Dar Sadr, Byrwt, Altb'h Alawla.

12. Aldby, Almfdl, Almfdlyat, Thqyq: Ahmd Shakr, 'bd Alslam Harwn, Dar Alm'arf, Alqahrh, Altb'h Alsab'h.

13. Abn Dryd, Mhmd Bn Alhsn: Jmhrt Allghh, Dar Sadr, Byrwt.

14. Dw Alrmh, Ghylan Bn 'qbh (1998). Dywanh, Thqyq: 'mr Altba', Dar Alarqm Bn Aby Alarqm, Byrwt, Altb'h Alawla. 
15. Alhsyny, Sdr Aldyn (1968). Anwar Alrby' Fy Anwa' Albdy', Thqyq: Shakr Hady Shakr, Mtb't Aln'man, Alnjf Alashrf.

16. Aljahz, 'mrw Bn Bhr (1975). Albyan Waltbyyn, Thqyq: 'bd Alslam Mhmd Harwn, Mktbt Alkhanjy Bmsr, Altb'h Alrab'h.

17. Aljrjany, 'bd Alqahr(1991). Asrar Alblaghh, T'lyq: Mhmwd Mhmd Shakr, Dar Almdny, Jdh.

18. Abn Jny, 'thman S'd (1986). Alkhsa's, Thqyq: Mhmd 'la Alnjar, Alhy'h Almsryh Al'amh Llktab, Alqahrh.

19. Aljwhry, Esma'yl Bn Hmad (1979). Taj Allghh Wshah Al'rbyh, Thqyq: Ahmd 'bd Alghfwr, Dar Al'lm Llmlayyn, Byrwt, Altb'h Althanyh.

20. Alkhtaby, Ahmd Bn Mhmd Bn Ebrahym (1983). Ghryb Alhdyth, Thqyq: 'bd Alkrym Ebrahym Al'zbawy, Dar Alfkr, Dmshq.

21. Alkhtyb Al'mry, Yasyn (2000). Alrwdh Alfyha' Fy A'lam Alnsa', Thqyq: Hsam 'bd Alhkym, M'sst Alktb Althqafyh, Byrwt, Altb'h Alawla.

22. Alkhnsa', Tmadr, Dywanha, Shrhh Wdbth: 'mr Altba', Dar Alarqm, Byrwt.

23. Alsbky, Bha' Aldyn Ahmd Bn 'ly Bn 'bd Alkafy (2003). 'rws Alafrah Fy Shrh Tlkhys Almftah, Thqyq: 'bd Alhmyd Hndawy, Almktbh Al'sryh, Byrwt, Altb'h Alawla.

24. Abn Sydh, Abw Alhsn Bn Esma'yl Alandlsy, Almkhss, Thqyq: Ljnh Ehya' Altrath, Mnshwrat Dar Alaman Aljdydh, Byrwt.

25. Abn Thabt, Hsan (1974). Dywanh, Thqyq: Wlyd 'rfat, Dar Sadr, Byrwt.

26. Altrmdy, Mhmd Bn 'ysa (1999). Aljam' Alshyh (Snn Altrmdy), Thqyq: Ahmd Mhmd Shakr, Mstfa Mhmd Hsyn Aldhby, Dar Alhdyth, Alqahrh.

27. Altrmdy, Mhmd Bn 'ysa (2005). Alshma'l Almhmdyh, Thqyq: Syd 'mran, Dar Alhdyth, Alqahrh, Altb'h Alawla.

28. Alzbydy, Mrtda (1965). Taj Al'rws Mn Jwahr Alqamws, Thqyq: 'bd Alstar Ahmd Fraj, Dar Alhdayh, Alkwyt.

29. Alzhry, Mhmd Bn S'yd (2001). Ktab Altbqat Alkbyr, Thqyq: 'ly Mhmd 'mr, Mktbt Alkhanjy, Alqahrh, Altb'h Alawla.

30. Abn Zkrya Alqzwyny, Ahmd Bn Fars (1986). Mjml Allghh, Thqyq: Zhyr 'bd Almhsn Sltan, M'sst Alrsalh, Byrwt, Altb'h Althanyh. 